\title{
Top-down estimation of carbon monoxide emissions from the Mexico Megacity based on FTIR measurements from ground and space
}

\author{
W. Stremme ${ }^{1}$, M. Grutter ${ }^{1}$, C. Rivera ${ }^{1, *}$, A. Bezanilla ${ }^{1}$, A. R. Garcia ${ }^{1}$, I. Ortega ${ }^{1, * *}$, M. George ${ }^{2}$, C. Clerbaux ${ }^{2}$, \\ P.-F. Coheur ${ }^{3}$, D. Hurtmans ${ }^{3}$, J. W. Hannigan ${ }^{4}$, and M. T. Coffey ${ }^{4}$ \\ ${ }^{1}$ Centro de Ciencias de la Atmósfera, Universidad Nacional Autónoma de México, México City, México \\ ${ }^{2}$ UPMC Univ. Paris 06; Université Versailles St-Quentin; CNRS/INSU, LATMOS-IPSL, Paris, France \\ ${ }^{3}$ Spectroscopie de l'Atmosphère, Service de Chimie Quantique et Photophysique, Université Libre de Bruxelles (U.L.B.), \\ Brussels, Belgium \\ ${ }^{4}$ Atmospheric Chemistry Division, NCAR, Boulder CO, USA \\ * now at: Facultad de Ciencias, Universidad Nacional Autónoma de México, México City, México \\ *** now at: University of Colorado, Boulder, CO, USA
}

Correspondence to: M. Grutter (grutter@unam.mx), W. Stremme (stremme@atmosfera.unam.mx)

Received: 7 September 2012 - Published in Atmos. Chem. Phys. Discuss.: 21 November 2012

Revised: 25 January 2013 - Accepted: 28 January 2013 - Published: 1 February 2013

\begin{abstract}
Continuous carbon monoxide (CO) total column densities above the Universidad Nacional Autónoma de México (UNAM) campus in Mexico City have been derived from solar absorption infrared spectroscopic measurements since October 2007. Its diurnal evolution is used in the present study in conjunction with other ground-based and satellite data to develop a top-down emission estimate of the annual $\mathrm{CO}$ emission of the Mexico City Metropolitan Area (MCMA). The growth-rate of the total column around noon under low ventilation conditions is calculated and allows us to derive the average surface emission-flux at UNAM, while similar measurements taken at the edge of the MCMA in Tecámac provide information on background $\mathrm{CO}$ levels in the Mexico basin. Based on $3 \mathrm{yr}$ of measurements, $\mathrm{CO}$ column measurements from the Infrared Atmospheric Sounding Interferometer (IASI) satellite instrument are used to reconstruct the spatial distribution of this anthropogenic pollutant over the MCMA. The agreement between the measured columns of the satellite and ground-based measurements is excellent, particularly when a comparison strategy based on time-displaced air masses is used. The annual emission of the Mexico Megacity is estimated to be $(2.15 \pm 0.5) \mathrm{Tg} \mathrm{yr}^{-1}$ for the year 2008, while the official inventory for that year reported $1.6 \mathrm{Tg} \mathrm{yr}^{-1}$. The difference is slightly higher than the
\end{abstract}

conservative uncertainty estimated in this work suggesting that the emission might be underestimated by the conventional bottom-up method. A larger discrepancy is found in the spatial distribution of the emissions, when comparing the emission flux over UNAM (derived from the ground-based measurement) with that of the inventory integrated over a representative area. The methodology presented here represents a new and useful strategy to evaluate the contribution of megacities to the global anthropogenic gas emissions. Additionally, three different strategies to compare ground and space-based measurements above an inhomogeneous and strongly contaminated area like Mexico City are presented and discussed.

\section{Introduction}

Carbon monoxide (CO) is produced from the oxidation of methane and non-methane hydrocarbons, either from the incomplete combustion of fossil fuels or burning of vegetation (Finlayson-Pitts and Pitts, 2000). In the Mexico City Metropolitan Area (MCMA), CO is emitted mainly by lightduty motor vehicles in which there are more than 4.5 million of vehicles registered (SMA-GDF, 2010a). All vehicles are 
required to verify their emissions prescribed to local regulations. The upper permissible limit for the emission of $\mathrm{CO}$ in 1994 or later model vehicles is $1-2 \%$ of the total volume of gases leaving the exhaust, depending on vehicle type. However, for models older than 1994, the CO content of gases leaving the exhaust can be as high as 4-6\% (SEMARNAT, 2006).

From the 4.5 million vehicles circulating in the MCMA, $84.02 \%$ are private cars (including pick ups), $3.45 \%$ are taxis, $2.37 \%$ belong to the public transportation, $5.24 \%$ are motorcycles and $4.92 \%$ are medium and heavy duty trucks. In total, approximately $95 \%$ of the vehicles run on gasoline, $4 \%$ on diesel and $1 \%$ on LP (liquid petroleum) gas (SMAGDF, 2010a). Most of the vehicles running on gasoline use Magna gasoline produced by the state-owned company PEMEX with an octane rating of 87 and a total sulfur content of $500 \mathrm{ppm}$ (PEMEX, 2008). From the 2008 report on national fuel consumption there were 257.8, 31.3, 18.3 and 121.2 million barrels consumed of Magna gasoline, Premium gasoline, industrial diesel (low sulfur) and regular diesel, respectively (PEMEX, 2011), of that $18 \%, 16 \% 7 \%$ and $11 \%$ correspond to that consumed in the MCMA (SMA-GDF, 2010a).

The MCMA is centred at $19.4^{\circ} \mathrm{N}$ and $99.1^{\circ} \mathrm{W}$ at an altitude of $2200 \mathrm{~m}$ a.s.l., it covers an area of approximately $7732 \mathrm{~km}^{2}$ and is located in a basin surrounded by mountains to the east, south and west. According to the 2010 census (INEGI, 2011), it has a population of slightly over 20 million people and has doubled since 1975 . The city's air quality is monitored by a network operating since 1984 which is run by the local government's ministry of the environment (Secretaría de Medio Ambiente del Gobierno del Distrito Federal: SMA-GDF). CO is currently monitored at the ground, together with other pollutants, at 24 stations around the MCMA (SIMAT, 2011).

The trend of CO concentrations in the MCMA has been decreasing over the years when compared to 1989 pollution levels. The daily maximum $\mathrm{CO}$ concentration reached a yearly average of $8.7 \mathrm{ppm}$ in 1991 and dropped to $1.54 \mathrm{ppm}$ in 2008 (SMA-GDF, 2009; SIMAT, 2011). According to the 2008 emissions inventory for the MCMA, the transportation sector accounts for $99 \%$ of the total CO emissions. The emissions reported for the years 2000, 2004 and 2008 were $2.03,1.79$ and $1.57 \mathrm{Tg} \mathrm{yr}^{-1}$, respectively (SMA-GDF, 2010a). These estimates are calculated with standard procedures which are based on a bottom-up approach. The largest uncertainties in that methodology include the poor knowledge of adequate emission factors for the conditions of Mexico City, the fleet's characteristics and age, but also the accumulated trip duration and driving patterns.

While monitoring networks, such as the one in the MCMA, provide very useful information about concentration of contaminants at ground level, pollutants are also present at different altitudes and therefore column measurements (integrated concentration of a certain pollutant over a vertical path) provide additional information.
Solar absorption Fourier Transform Infrared Spectroscopy (FTIR) is a measurement technique widely used to retrieve columns or volume mixing ratios of $\mathrm{CO}$ from ground, airborne, shipborne and satellite platforms. Initial work in 1995, by Pougatchev and Rinsland (1995) developed a methodology to retrieve the vertical distribution of CO from groundbased spectroscopic measurements of infrared solar spectra. Long term trends in the CO content of Moscow's boundary layer have been observed since 1972 (Rakitin et al., 2012). Rakitin et al. (2011) conducted ground based CO column measurements in an urban (Moscow) and a rural site in Russia using a grating spectrometer coupled to a solar tracking system. Their main finding was that the observed variations on CO columns were principally dependent on wind velocity and temperature inversions.

Recently, anthropogenic gas emissions in the urban agglomeration around Los Angeles, United States (Wunch et al., 2009) and Paris, France (Té et al., 2012) have been studied. Wunch et al. (2009) found a strong correlation in the column anomalies of $\mathrm{CO}$ and $\mathrm{CO}_{2}$ and $\mathrm{CH}_{4}$ measured in the basin around Los Angeles and determined the ratios in the emission of these gases.

In the MCMA, de Foy et al. (2007) used vertical column measurements of $\mathrm{CO}$, derived from FTIR spectrometers, to constrain the $\mathrm{CO}$ emission in models and evaluate the emission inventory of the MCMA. The objective was to identify the most appropriate vertical dispersion scheme of $\mathrm{CO}$ in the MCMA and the modeled CO concentrations using the emission inventory values were found to be in agreement with the measurements. Since 2007, solar absorption FTIR measurements have been conducted regularly from which $\mathrm{CO}$ total columns have been reported and used to evaluate the mixing layer height above the UNAM campus (Stremme et al., 2009).

Clerbaux et al. (2008a) demonstrated the feasibility of using satellite observations to monitor pollution sources and transport analyzing CO averaged between 2000 and 2007 derived from observations of the MOPITT (Measurements of Pollution in the Troposphere) instrument. A validation of the MOPITT instrument was conducted by Emmons et al. (2009) by comparing $\mathrm{CO}$ measurements from aircraft measurements with MOPITT observations and a significant (about $20 \%$ ) positive bias in the total column of CO measured by MOPITTv.3 was found. Angelbratt et al. (2011) analyzed ground-based solar FTIR spectra from the Network for the Detection of Atmospheric Composition Change (NDACC), identifying negative linear trends from partial columns of $\mathrm{CO}$ and $\mathrm{C}_{2} \mathrm{H}_{6}$ during 1996-2006 above Europe.

Most recently Kerzenmacher et al. (2012) found that the Infrared Atmospheric Sounding Interferometer (IASI) CO total column product for 2008 from the most recent retrieval (Hurtmans et al., 2012) compare well on average with measurements on several remote sites of NDACC-stations. No bias was detected, which is a favourable precondition to evaluate and use this IASI product for an inhomogeneous and 
Table 1. Overview of the CO column measurements from the three FTIR instruments used for the top-down emission estimation.

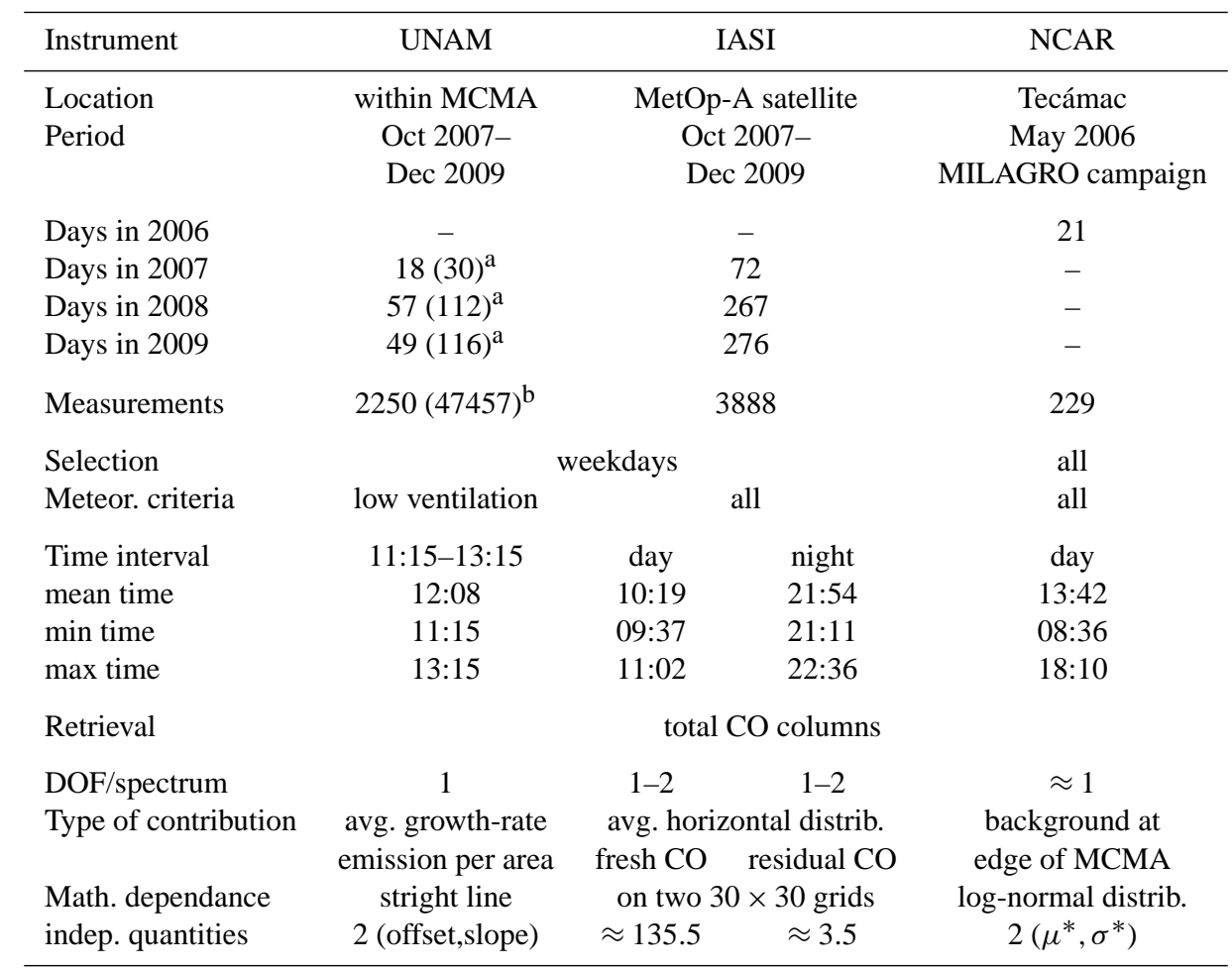

a Number of days at any meteorological condition.

b Number of all measurements taken at any time.

strongly contaminated area above a megacity (a metropolitan area with a total population of more than 10 million people).

This paper presents results of CO column measurements conducted at the UNAM station in Mexico City using a ground-based FTIR instrument, satellite data from the IASI instrument and a calculation strategy as an alternative way of estimating emissions of the entire metropolitan area. This is a top-down approach employing several steps: (1) determining the growth-rates of the total $\mathrm{CO}$ vertical columns measured with high-temporal resolution. Here the time period is optimized and days with horizontal ventilation are filtered out in order to minimize other effects affecting the growth-rate. (2) Measurements conducted during 2006 using a high resolution FTIR- Instrument located at the edge of the MCMA, are used to estimate the column $\mathrm{CO}$ background in the Valley of Mexico. (3) The spatial distribution of CO is obtained from satellite data and used to extrapolate the locally derived emission to the entire metropolitan area. (4) The emission is then extrapolated to $24 \mathrm{~h}$ with the known daily emission behaviour. The results are compared with the official emissions reported for the year 2008, the uncertainties have been estimated and the potential and limitations of this method are discussed.

\section{Methodology}

In this section we present the retrieval strategies of the total CO columns. Three different instruments and retrieval codes are used to obtain the CO columns: at the UNAM station, at the Tecámac site and over the area 99.5-98.5 ${ }^{\circ} \mathrm{W}$ and $18-20^{\circ} \mathrm{N}$ measured from the IASI instrument on board the MetOp-A satellite. Table 1 gives an overview of the measurements. Also in this section, the strategy used for calculating a local flux from the column growth-rate is described and a method is presented for obtaining the spatial distribution of $\mathrm{CO}$ used in the top-down estimation of the annual emission of this pollutant over the entire metropolitan area.

\subsection{Ground measurements and retrieval of total columns}

In this subsection we present the observation sites, instruments, monitoring and retrieval strategies of the solar absorption ground measurements which are used in the following sections.

UNAM instrument: The ground-based spectra at the UNAM campus were taken with a Bruker OPAG22 interferometer at $0.5 \mathrm{~cm}^{-1}$ spectral resolution. The interferometer is part of a Scanning Infrared Gas Imaging System (SIGIS) built to measure infrared emission spectra at 
different pointing directions used in various applications (Grutter et al., 2008a; Grutter et al., 2008b; Stremme et al., 2012; Krueger et al., 2013) but adapted to measure solar absorption spectra as described by Stremme et al. (2009, 2011). It consists of a scanning mirror which directs the solar radiation to a 1/4-telescope prior to entering the spectrometer, which is equipped with a $\mathrm{KBr}$ beamsplitter and a MCT detector. The vertical column of $\mathrm{CO}$ was calculated with SFIT2v.393 (years: 2007-2008) and SFIT2v.394 (2009). Both versions have been compared and show almost identical results for CO. The retrieval adjusts only the concentration in the boundary layer and reaches a comparable good sensitivity (the total column averaging kernel $\approx 1$ ) in the altitude of interest $(0-4 \mathrm{~km}$ above surface). In this work it will be used as a true CO column measurement without its averaging kernel. The retrieval, its averaging kernel and its most important errors have been described in Ortega (2009) and Stremme et al. (2009) with more detail.

NCAR instrument: The background $\mathrm{CO}$ total column at the edge of the MCMA, but still within the basin, was determined from FTIR solar absorption measurements taken during the Megacity Initative: Local and Global Research Observations (MILAGRO) field campaign (Molina et al., 2010). The spectra were recorded during March 2006 at the T1-site located in Tecámac University, located near developing urban areas near the highway to Pachuca, NE of the MCMA $\left(19.7^{\circ} \mathrm{N}, 99.0^{\circ} \mathrm{W}\right.$ and $2273 \mathrm{~m}$ a.s.l.).

Infrared observations during the MILAGRO campaign were made with a high resolution solar viewing mobile FTS at $0.06 \mathrm{~cm}^{-1}$ spectral resolution. The instrument and analysis has been deployed on many observation campaigns both airborne (e.g. Coffey et al., 2008) and ground-based (e.g. Hannigan et al., 1998) which contain detailed descriptions of the instrument and analysis techniques. During the MILAGRO program and in particular the analysis of $\mathrm{CO}$ was performed using version 3.92 of SFIT2 (Rinsland et al., 1982) that employs the optimal estimation technique described by Rodgers (1990). Carbon monoxide spectral features at 2151, 2154.5 and $2158 \mathrm{~cm}^{-1}$ were taken from the high signal-tonoise spectra (typical $>800$ ) and fit simultaneously to retrieve the coarse $\mathrm{CO}$ mixing ratio profile. The forward model used daily NCEP temperature and pressure analyses profiles. Spectral data for the line-by-line calculations were taken from the 2004 version of HITRAN (Rothman et al., 2005) and the solar background spectral data and model of Hase et al. (2006) was used. Observations were made throughout the day using a computer guided mirror followed by a dynamic tracker controlled by a quadrupole diode feedback system to lock the solar image on to the instrument entrance aperture. The slant path profiles were integrated and converted to the vertical total columns reported here using the local daily NCEP analyses.

The CO columns shown in Fig. 1 were measured during March 2006 within the Mexican basin (2273 m a.s.l.) but at the edge of the MCMA (see map in Fig. 6). The time-series

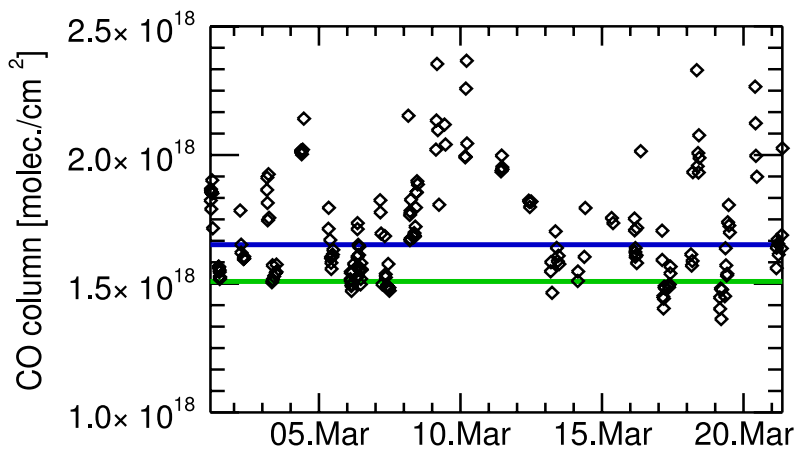

Fig. 1. CO column measurements at the edge of the MCMA. The observed variability can be explained reasonably well by the wind pattern classification of de Foy et al. (2008) (see text). The columns consist of the background value plus an additional part of fresh $\mathrm{CO}$ depending on the wind direction and strength. As columns cannot be negative we assume a log-normal distribution. The two horizontal lines represent the median value (blue) and the green, $\mu^{*} / \sigma^{*}$, calculated from the average of the natural logarithm of the columns separating an interval of the lowest $15.85 \%$ in a log-normal distribution $\left(\mu^{*}=\operatorname{Exp}(\operatorname{avgr} .(\ln (x))), \sigma^{*}=\operatorname{Exp}(\operatorname{stdev} .(\ln (x)))\right)$. This lower limit (green) lies at $1.51 \times 10^{18}$ molec cm $^{-2}$ and is used to define the border of the MCMA CO-footprint.

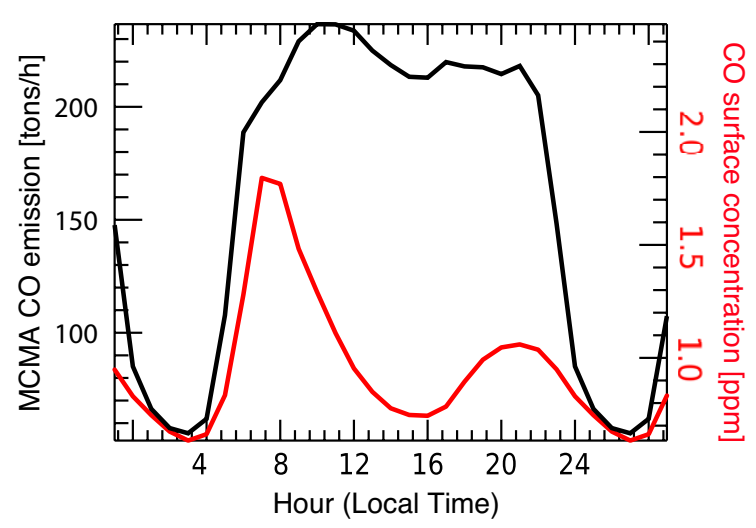

Fig. 2. The black line shows the average temporal behaviour of the $\mathrm{CO}$ emissions in Mexico City per hour and is taken from the official inventory of 2008 (SMA-GDF, 2010a). The red line shows the average temporal evolution of $\mathrm{CO}$ surface concentration averaged over the 5 nearest monitoring sites during 2007-2009.

shows variations which result from both local emissions and transport events from the south bringing contaminated air of Mexico City. The transport events during the MILAGRO campaign are classified by de Foy et al. (2008). In that study, the days 6-8,13,16-17 and 21 March 2006 were classified as having air parcels transported from the North and Fig. 1 shows low values for those same days. Thus, most of the time the measurements represent $\mathrm{CO}$ columns of uncontaminated clean background in the basin and can be used as a reference for defining background levels in the region. 
The overall mean of the CO column measurements at the Tecámac site during March 2006 is $1.72 \times 10^{18}$ molec cm $^{-2}$. Two lines (blue and green) are drawn in Fig. 1 at 1.65 and $1.51 \times 10^{18} \mathrm{molec}^{-2}$, representing the median, which separates an interval of the lower and upper half, and the ratio $\mu^{*} / \sigma^{*}$ calculated from the exponent of the average and the standard deviation of the natural logarithm of the columns. The value $\mu^{*} / \sigma^{*}$ separates an interval of the lowest $15.85 \%$ in a log-normal-distribution (Limpert et al., 2001). This value $\left(1.51 \times 10^{18}\right.$ molec $\left.\mathrm{cm}^{-2}\right)$ is used to define a lower limit of the CO column amount in the urban areas of the MCMA and will be used to mark the border of the CO-footprint obtained from IASI satellite data in Fig. 6. The uncertainty of this lower limit is estimated to be around $3.5 \%$ calculated from the precision of the measurements.

\subsection{Column growth-rate and emission flux}

The section describes how the mean emission flux at UNAM can be reconstructed from continuous measurements of the gas columns. The total column of carbon monoxide over Mexico City is dominated by the pollution produced by traffic. The typical diurnal cycle of $\mathrm{CO}$ as seen from in situ instruments at the surface, presents a strong peak in the morning hours and then decreases as the mixing layer height grows and dilutes all pollutants. This is illustrated in Fig. 2 (red trace), where the surface concentration of the 5 nearest stations from the SMA-GDF monitoring network (PED, PLA, SUR, TAX, UIZ full name and locations see Table 4) have been averaged over the 2007-2009 time period. The mean diurnal cycle also shows an increase in the afternoon.

The column measurement should be independent of the diurnal change of the mixing layer height such that an increase over the day will, under certain conditions, be associated mainly with new emissions. This general assumption is the basis of what is proposed in this paper although several aspects need to be taken into consideration. Enhancements due to horizontal transport should be avoided, thus low ventilation will be a criterion as described later. Chemical processes of $\mathrm{CO}$ are comparably slow on the time scale of hours and therefore its abundance within the mixing layer is thought to be dominated by ventilation and emission. Also, a trend, an annual cycle or possible anomalies in the CO column resulting from fires or other sources should not play a crucial role for determining the daily growth-rate as is done here, although the errors associated to these are considered and discussed in Sect. 4.3.

Figure $3 \mathrm{a}, \mathrm{b}$ show all total vertical CO columns measured at UNAM and have been separated in days with high and low ventilation, respectively. Typically, there is little to no ventilation between 07:00 and 13:00 LT in the Mexican basin and the afternoon and evening winds tend to refresh the air in the city with increased wind speeds (de Foy et al., 2008). We selected low ventilation days using cluster analysis, which defines for a given data set, different groups of elements with
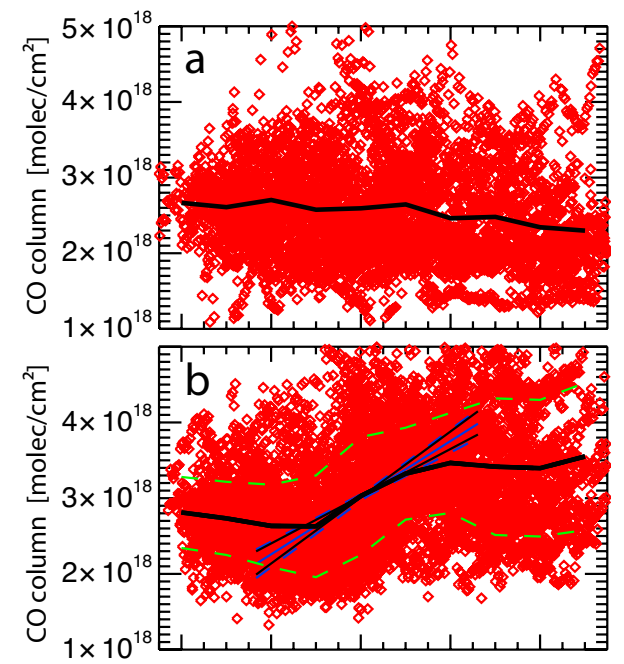

Fig. 3. The evolution of the total vertical CO column measured between 2007 and 2009 over the UNAM campus in Mexico City $\left(19.33^{\circ} \mathrm{N}, 98.65^{\circ} \mathrm{W}\right)$ is shown as black traces. Columns measured on days with appreciable ventilation (a) display a different diurnal pattern than on days with minimal ventilation (b). The classification is done by a cluster analysis using wind information of 6 meteorological stations around the UNAM campus (see text). The average diurnal behaviour of weekdays only and with low ventilation, together with its standard deviation (green dashed lines) is shown in plot (b). The growth-rate in the chosen interval is shown as a fitted straight line (blue) and its error is given by the $95 \%$ confidence interval (blue dashed hyperbola) and their asymptotes as black straight lines.

similar properties. The set is given by the days between $2007-$ 2009 and the analysis assigns each measurement day to one of these groups (e.g. the group of low or high ventilation).

As with the surface concentrations, the meteorological data are taken from 6 surrounding stations of the SMA-GDF network. The classification is quite robust and does not depend significantly on the number of cluster points (which is chosen), weighting and other criteria. 622 days in this time period (almost two-thirds of the days), were classified as days with low ventilation and have average wind speeds below $1.5 \mathrm{~m} \mathrm{~s}^{-1}$ between 08:00 and 12:00 LT.

A growth-rate of the column within a specific time interval is shown in Fig. 3c. One must understand the factors affecting changes in the total columns in order to avoid unwanted results. If $\mathrm{CO}$ is treated as a chemically inert gas, the average of the observed column growth-rate $\frac{\mathrm{dTC}}{\mathrm{d} t}$ is given by the four terms shown in Eq. (1).

$$
\begin{aligned}
& \frac{\mathrm{dTC}}{\mathrm{d} t}=\left(\frac{\partial \mathrm{TC}}{\partial t}\right)_{\text {emission }}+ \\
& \underbrace{\left.\frac{\partial \mathrm{TC}}{\partial t}\right)_{\text {inhomogeneity }}}_{\nabla_{\phi, \theta} \mathrm{SC}(\phi, \theta) \partial_{t} \boldsymbol{n}(\phi, \theta)}+\underbrace{\left(\frac{\partial \mathrm{TC}}{\partial t}\right)_{\text {diffusion }}}_{\mathrm{TC} \cdot\left(\nabla \cdot \boldsymbol{V}_{\mathrm{CO}}\right)}+\underbrace{\left(\frac{\partial \mathrm{TC}}{\partial t}\right)_{\text {advection }}}_{(\nabla \mathrm{TC}) \cdot \boldsymbol{V}}
\end{aligned}
$$


For a horizontally homogeneous $\mathrm{CO}$ distribution and without ventilation, only the direct emission $\left(\frac{\partial \mathrm{TC}}{\partial t}\right)_{\text {emission would }}$ change the measured total column TC, but before 10:00 LT, the column in Fig. $3 b$ does not show the desirable linear growth due to fresh emissions when traffic has already peaked at 08:00 LT (see diurnal cycle in Fig. 2). An explanation for this is that a horizontal inhomogeneity of $\mathrm{CO}$ exists in the early morning when mixing has not taken place. As a result, the measured slant columns (SC) by this technique taken at high sun zenith angles $(\theta)$ are not converted to correct values of TC.

As there is usually more contamination in the east of the UNAM campus, a slight decrease of the retrieved TC with decreasing $\theta$ and changing of the azimuth angle $(\phi)$ from east to south, is observed. The inhomogeneity $\nabla_{\phi, \theta} \operatorname{SC}(\phi, \theta)$ diminishes significantly later on mainly due to turbulent mixing but also $\theta$ has decreased sufficiently so that this bias can be neglected. The latter argument might be described as the temporal change of the projection vector $\partial_{t} \boldsymbol{n}(\phi, \theta)$, which symbolizes the conversion from the SC depending on $\phi, \theta, \cos (\theta)$ to the TC.

The third term TC $\cdot\left(\nabla \cdot v_{\mathrm{CO}}\right)$ in Eq. (1) represents the dilution through ventilation and might correspond to a decay of perturbation (as $\mathrm{TAU}_{\text {trans }}$ described by Yurganov et al., 2011). Ventilation hinders accumulation and is responsible for the column starting each day with approximately the same value. The total CO column in and near the MCMA is systematically decreasing with the increasing wind speeds in the afternoon. The separation of the $\mathrm{CO}$ transport into part 3 and 4 in Eq. (1) is motivated from the fact that part 4 is directly accessible to measurements. However the description of the $\mathrm{CO}$ flux by total column values, their gradients and the wind velocity is not complete.

Diffusion near a point source or the border between urban and rural conditions might theoretically produce a $\mathrm{CO}$ transport even in the opposite direction from where the wind comes and an impact on the growth-rate of the total column is expected. If part 3 in Eq. (1) has a non zero value the mean velocity of all molecules differs from the mean velocity of the $\mathrm{CO}$ molecules $\left(\boldsymbol{v}_{\mathrm{CO}}\right)$ and part 3 in Eq. (1) represents the correction to the growth-rate of the column due to the diffusion.

$v_{\mathrm{CO}}-\boldsymbol{v}$ might not directly be accessible to measurements, but the turbulent diffusion depends on wind speed $|\boldsymbol{v}|$, the diffusion term here might be better described by a phenomenological decay-rate of the total column anomaly $\left(\mathbf{D}_{\mathrm{TC}}\right)$ and the relation $\frac{\partial \mathrm{TC}}{\partial t}$ diffusion $=-\mathbf{D}_{\mathrm{TC}}(|\boldsymbol{v}|) \cdot \Delta \mathrm{TC}$. The contribution is not estimated quantitatively, but it is plausible that this term increases (a) with the difference between the total column anomaly, urban minus the background level and (b) with the wind speed.

Choosing a correct interval for calculating the growthrate is therefore crucial. There is a trade off between i) low systematic errors which means an interval which is not significantly affected by horizontal inhomogeneity at high sun

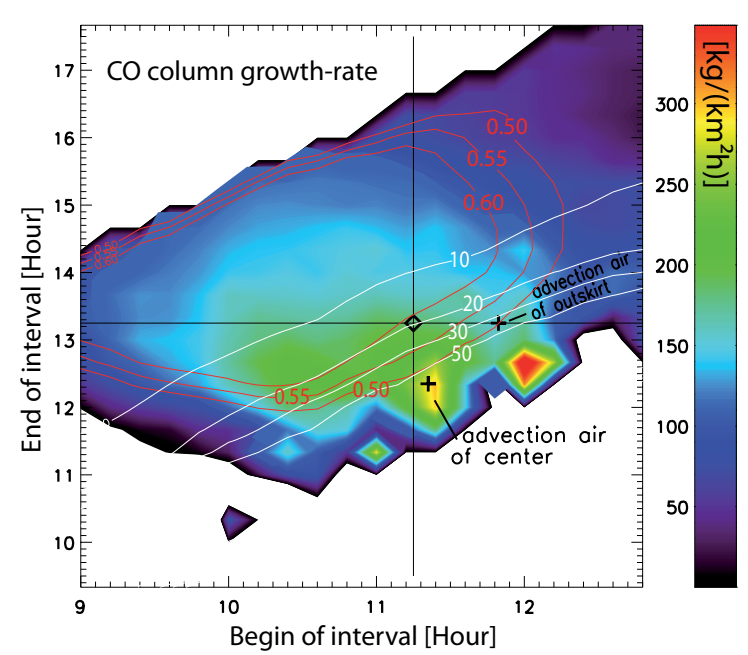

Fig. 4. Sensitivity of the calculated emission flux to the chosen time interval. False-color shows the resulting emission fluxes at UNAM around noon. Red contour lines mark in the parameter-space the value of $R$ (Pearson correlation coefficient of the resulting dataset). White contour lines show the error of the obtained emission flux in $\mathrm{kg} \mathrm{km}^{-2} \mathrm{~h}^{-1}$ (taken from the $95 \%$ confidence interval). The finally chosen time interval is marked as a diamond with a black horizontal line at 13:15 and vertical line at 11:15. Two crosses mark a local maximum and minimum, referred in the text.

zenith angles in the mornings or increased ventilation in the afternoons and ii) the random error which means that the time interval is still large enough to obtain a significant result for the mean slope. Figure 4 presents a map of the calculated emission fluxes (slope in Fig. 3) using different start and end times. The chosen interval (11:15 to 13:15 LT), marked with a diamond in Fig. 4, has a Pearson's correlation coefficient $R$ of almost 0.6 , which proves the linear behavior of the sample. A random error (precision) of $\approx 10 \%$ (at a $95 \%$ confidence level) with this $2 \mathrm{~h}$ time-interval is achieved. ${ }^{1}$

It is very likely that the bias resulting from a larger solar zenith angle together with the inhomogeneity factor is still small at 10:30 LT, but this error is not quantified and therefore avoided at the cost of the larger random error. Ending the interval at a later time results in a systematically lower growth-rate.

Both effects of inhomogeneity and ventilation go in the same direction and lower the growth-rate systematically, however, there is another source of systematic error included in the fourth term of Eq. (1). The average column in Fig. 3b, even when classified by low ventilation, contains a positive advection term. The contribution of advected $\mathrm{CO}$ molecules to the growth-rate is a function of the time of the day and

\footnotetext{
${ }^{1} \mathrm{~A}$ more sophisticated calculation of the growth-rate might improve the analysis; e.g. subtracting an individual mean value for the data used of each day prior to the linear regression decreases the random error from $10 \%$ to $8.5 \%$ while the result does not change significantly.
} 
depends on the average wind direction and velocity and on the spatial distribution of $\mathrm{CO}$. This term affects the results of the emission per area and has to be corrected. The advection term was calculated by an "averaged wind-propagation footprint". It is also used for the comparison of ground-based and satellite measurements, which are not coincident in time. Its calculation is described in more detail in the Supplement.

Through continuous monitoring, a statistically relevant emission flux can be determined from the mean column growth-rate. The combined variability of both traffic and wind direction produces a strong inhomogeneous $\mathrm{CO}$ emission and leads to noise and small scale patterns in the column measurements of some days, even if they are classified with "low ventilation". This effect prevents the data from being suitable for a linear fit. However, such small scale systematic patterns on single days are cancelled out, a large set of days is used so that these patterns are converted to random noise. In total for this study, $2260 \mathrm{CO}$-column measurements were used between 2007 and 2009 and the resulting growth-rate in the chosen time interval, presented in Fig. 5c corresponds to an emission per area and time of $(174 \pm 20) \mathrm{kg} \mathrm{km}^{-2} \mathrm{~h}^{-1}$. The uncertainty is calculated from the $95 \%$ confidence interval.

\subsection{Spatial distribution from satellite measurements}

In this section we describe a technique to reconstruct the mean $\mathrm{CO}$ distribution with high resolution based on satellite data. A high spatial resolution is necessary to account for the strong inhomogeneity in the MCMA and a key ingredient for the top-down estimation in Sect. 2.4. The Infrared Atmospheric Sounding Interferometer (IASI) was launched in October 2006 on board the MetOp-A satellite. It was developed by the Centre National d'Etudes Spatiales (CNES) in the framework of a co-operation agreement with the European Organisation for the Exploitation of Meteorological Satellites (EUMETSAT) (Clerbaux et al., 2009; Hilton et al., 2012). It consists of a FTIR which measures thermal spectra of the Earth with high radiometric quality at $0.5 \mathrm{~cm}^{-1}$ spectral resolution, from 645 to $2760 \mathrm{~cm}^{-1}$. Data samples are taken at intervals of $25 \mathrm{~km}$ along and with a swath width of $2200 \mathrm{~km}$ across track, with samples at nadir having a diameter of about $12 \mathrm{~km}$. The $\mathrm{CO}$ column product has been retrieved with the Fast Optimal/Operational Retrieval on Layers for IASI (FORLI) algorithm (Hurtmans et al., 2012). The algorithm uses tabulated absorption cross-sections and calculates the $\mathrm{CO}$ profile on 19 layers with a constant $1 \mathrm{~km}$ thickness. The a-priori information for $\mathrm{CO}$ is constructed from profile ensembles (Turquety et al., 2008) based on modelresults (LMDz-INCA)(Hauglustaine et al., 2004), profile retrievals from the ACE-FTS spaceborne instrument (Clerbaux et al., 2008b) and aircraft based profile measurements from the project, Measurement of ozone, water vapour, carbon monoxide and nitrogen oxides by airbus in-service aircraft (MOZAIC) (Nedelec et al., 2003). The resulting covariance matrix shows a high variability $(65 \%)$ in the lowest layers

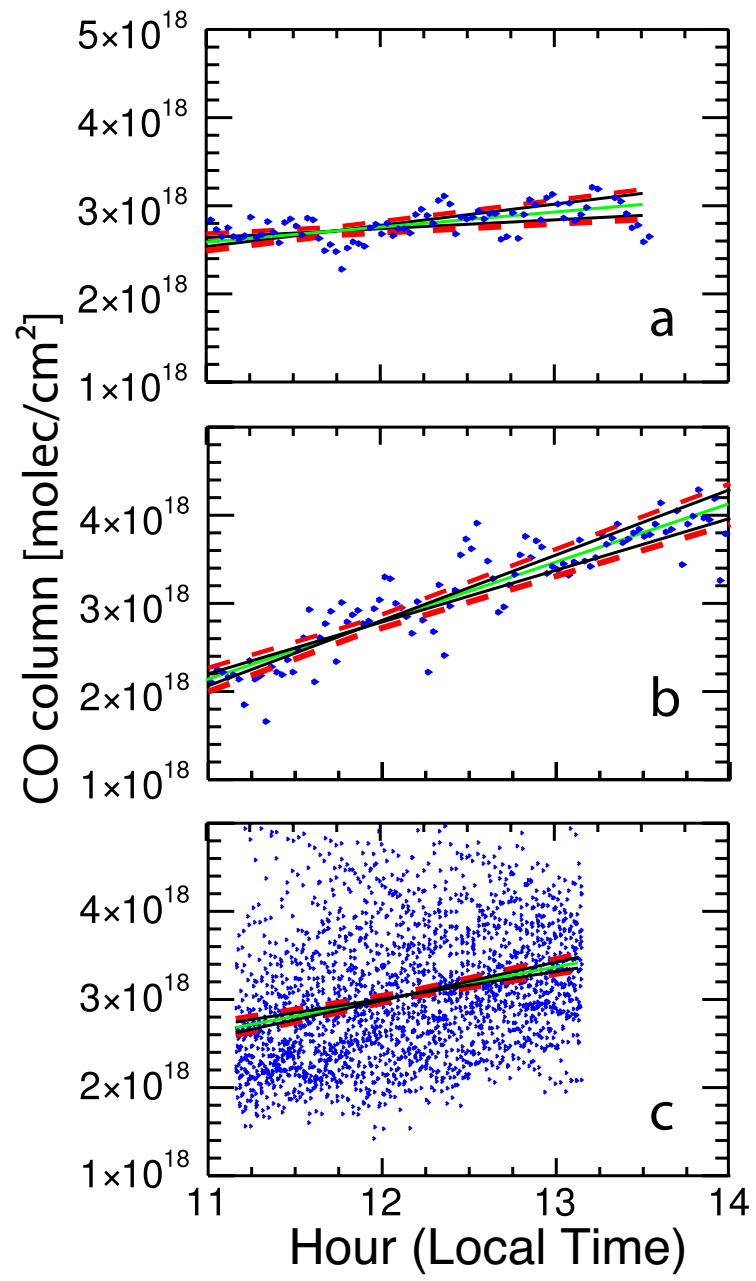

Fig. 5. Scatter plots of CO column measurements (blue dots) at UNAM on two typical days with low ventilation a) Sunday, 20 January 2008 and b) Monday, 21 January 2008, the following day. The linearly fitted growth-rates (green lines) reflect emission fluxes of $(105 \pm 13)\left(\mathrm{kg} / \mathrm{km}^{2} \mathrm{~h}\right)$ and $(309 \pm 25) \mathrm{kg} /\left(\mathrm{km}^{2} \mathrm{~h}\right)$, respectively. The CO column growth-rate between 11:15 and 13:15 LT on all days without ventilation is presented in c). Errors are taken from the 95\% confidence interval drawn as the dashed red lines and their asymptotes (black lines). The latter indicates the error in the slope (growth-rate) which reflects the average emission flux of $\mathrm{CO}$. The large dispersion originates from local or regional events as well as from a seasonal cycle, but the noise is compensated by the large dataset in c) and a significant value $(174 \pm 20) \mathrm{kg} /\left(\mathrm{km}^{2} \mathrm{~h}\right)$ for the emission flux of $\mathrm{CO}$ is calculated.

and a smaller variability (below $30 \%$ ) in the free troposphere (Hurtmans et al., 2012). A more detailed description of the FORLI-algorithm can be found in the recent work of Hurtmans et al. (2012) and CO column retrieved from IASI has been used for various studies (Yurganov et al., 2011; Pommier et al., 2010; Turquety et al., 2009; George et al., 2009; Kerzenmacher et al., 2012). 
The distributions of the average total $\mathrm{CO}$ column during the two overpasses (morning and evening) of MetOp-A is reconstructed from $3 \mathrm{yr}$ of IASI data for the area around Mexico City. The reconstruction is on a $30 \times 30$ grid $(\approx 3.7 \mathrm{~km}$ grid) and treated as an mathematically ill-posed problems (Mathematical problems or equations which do not have a unique solution.). As the vertical resolution of IASI is below 2 degrees of freedom (DOF) only the total CO columns $\left(\mathrm{TC}_{\mathrm{IASI}}\right)$ are taken in this work. The data set contains both measurements taken during the day $\left(\mathrm{TC}_{\mathrm{IASI}}\right)$ at 10:19LT on average and after sunset $\mathrm{TC}_{\mathrm{IASI}}^{\text {night }}$. The averaged column CO distribution over the MCMA differs between both overpass times and the total column sensitivities (the total column averaging kernel) are also different in both data sets. The profile (the average vertical $\mathrm{CO}$ distribution during morning overpass) is described by a CO profile which is linearly decreasing with altitude up to a fixed value in the tropopause and a mixing layer of $1 \mathrm{~km}$ thickness which has a constant volume mixing ratio of $\mathrm{CO}$. The horizontal resolution of the retrieved average $\mathrm{CO}$ distribution mainly depends on the constraint and not directly on the instrumental field of view (FOV), see Sect. 2.3.3. Therefore, we do not differentiate between the FOV of the different viewing angles of the IASI instrument, but we use here the nadir footprint, a circle with a diameter of $12 \mathrm{~km}$, for all IASI measurements.

\subsubsection{Annual mean CO distribution: forward model}

A linear forward model $\mathbf{K}$ simulates all measured columns by a linear transformation of an average $\mathrm{CO}$ distribution $\left(\boldsymbol{x}_{\text {avgr.CO }}\right)$ on a fine grid. It combines the footprint of each measurement with its averaging kernel and parametrized profiles. The vector $\epsilon$ contains the difference between measurements (column retrievals) and simulations. Each component describes the deviation of a retrieved $\mathrm{CO}$ column from the estimated mean value at each measurement (smoothed by the IASI kernel) plus the measurement noise error and other errors of the IASI retrievals.

$\mathrm{TC}_{\mathrm{IASI}}=\mathbf{K} \cdot \boldsymbol{x}_{\mathrm{avgr} . \mathrm{CO}}+\boldsymbol{\epsilon}$

Two values (background $\mathrm{CO}$, mixing layer $\mathrm{CO}$ ) for each gridpoint are used to describe a profile $\left(\operatorname{prf}_{\mathrm{co}}\right)$

$\operatorname{prf}_{\mathrm{CO}}=\lambda_{1} \cdot \operatorname{prf}_{1}+\lambda_{2} \cdot \operatorname{prf}_{2}$

The profiles are initialized with help from $\operatorname{prf}_{1}^{\mathrm{VMR}}$ and $\operatorname{prf}_{2}^{\mathrm{VMR}}$, in which $\operatorname{prf}_{1}^{\mathrm{VMR}}$ is a volume mixing ratio (VMR) profile which is linearly decreasing with height (it has the value 1.0 at the surface of the Mexican basin and 0 at $19 \mathrm{~km}$ ) and $\mathrm{prf}_{2}^{\mathrm{VMR}}$ is another profile which has the value 1.0 from the Mexican basin up to $1.5 \mathrm{~km}$ height and 0 above the mixing layer. For the use of the profiles together with the total column averaging kernel the VMR-profiles are multiplied by the partial air columns in each layer. The resulting profiles $\operatorname{prf}_{1}, \operatorname{prf}_{2}$ have now the unit molecules per layer. The averaging kernels or total column operators used in this work are calculated for and operated on the profiles in molec $\mathrm{cm}^{-2}$ per layer (partial columns) ${ }^{2}$. If $\operatorname{prf}_{1}$ and $\operatorname{prf}_{2}$ are normalized, $\lambda_{1}$ and $\lambda_{2}$ have the unit of columns.

Each CO column from IASI can be described as the sum of the average of the columns located inside the FOV of the IASI measurement, which are represented by $N_{\text {footprint }}$ grid points on the fine $(3.7 \mathrm{~km})$ grid, which allows for better modelling of a strong inhomogeneity and the difference between the measured column and the average $\mathrm{CO}$ column. The derived IASI column depends on the atmospheric state, on the instrumental sensitivity, the algorithm and the a priori information. For the sake of completeness we mention here that the dependence on the original a priori profile is eliminated, $\mathrm{TC}_{\text {IASI }}^{\text {day/night }}$ the total column of IASI is corrected by subtracting $\Delta \mathrm{TC}_{\mathrm{IASI}}^{\text {day } / \text { night }}=\left(\boldsymbol{g}^{t}-\mathrm{AKT}_{\mathrm{IASI}}^{\text {day } / \text { night }}\right) \boldsymbol{x}_{\mathrm{apr}}$, where $\boldsymbol{g}^{t}=$ $(111 \ldots 1)$ is the total column operator and $\mathrm{AKT}_{\mathrm{IASI}}^{\mathrm{day} / \mathrm{night}}$ the total column averaging kernel. This transformation is equivalent to a replacement of the original a priori by a zero-a prior profile (Rodgers, 2000) and simplifies Eq. (2).

In this work, $\epsilon$ depends on (a) measurement errors and (b) natural variability and describes statistically the difference of the measurements to the true annual mean $\mathrm{CO}$ column distribution. In other words, one part of $\epsilon$ results from short time variance and the other part results from random errors. We aim to find a profile $\hat{\mathrm{prf}}_{\mathrm{CO}}^{i}$, which represents the best estimation of the average vertical CO distribution $x_{\text {true }}^{i}$ on the $i$-th grid point at 10:19 LT (average includes all week days between October 2007 and January 2010).

$\mathbf{T C}_{\mathrm{IASI}}^{\mathrm{day}}=\mathrm{AKT}_{\mathrm{IASI}}^{\mathrm{day}} \cdot \frac{\sum_{i}^{N_{\text {footprint }}} \hat{\mathrm{prf}_{\mathrm{CO}}^{i}}}{N_{\text {footprint }}}+\boldsymbol{\epsilon}$

The total column averaging kernel describes the sensitivity to measure anomalies of the $\mathrm{CO}$ amount in different altitudes. It can be taken into account with some assumptions about the vertical distributions $\operatorname{prf}_{\mathrm{CO}}$. This a priori information could be realized through simplified probability distributions, smoothness constraints or as we do in this case through a parametrization. The advantage of the parametrization of $\operatorname{prf}_{\mathrm{CO}}^{i}$ is that we could reduce the dimensions of the equation from 19 layers to 2 parameters according to the background + residual CO distribution and a mixing layer at 10:19LT.

$$
\begin{aligned}
\mathbf{T C}_{\text {IASI }}^{\text {day }} & =\left(\mathrm{AKT}_{\text {IASI }}^{\text {day }} \cdot \operatorname{prf}_{1}\right) \cdot \frac{\sum_{i}^{N_{\text {footprint }}} \hat{\lambda}_{1}^{i}}{N_{\text {footprint }}} \\
& +\left(\mathrm{AKT}_{\text {IASI }}^{\text {day }} \cdot \operatorname{prf}_{2}\right) \cdot \frac{\sum_{i}^{N_{\text {footprint }}} \hat{\lambda}_{2}^{i}}{N_{\text {footprint }}}+\boldsymbol{\epsilon} \\
\mathbf{T C}_{\text {IASI }}^{\text {day }} & =\sum_{i}^{N_{\text {footprint }}}\left(\frac{\mathrm{AB}}{N_{\text {footprint }}} \cdot \hat{\lambda}_{1}^{i}+\frac{\mathrm{AM}}{N_{\text {footprint }}} \hat{\lambda}_{2}^{i}\right)+\boldsymbol{\epsilon}
\end{aligned}
$$

\footnotetext{
${ }^{2}$ Please note the different definitions: in related literature, i.e.: the total column averaging kernels here are called in Yurganov et al. (2011) "normalized" averaging kernels for total columns.
} 
$\mathrm{AB}:=\mathrm{AKT}_{\mathrm{IASI}}^{\mathrm{day} / \text { night }} \cdot \operatorname{prf}_{1}$ refers to a contribution of the background $\mathrm{CO}$ and $\mathrm{AM}:=\mathrm{AKT}_{\mathrm{IASI}}^{\mathrm{day}} \cdot \operatorname{prf}_{2}$ to fresh CO located in the mixing layer, both parts contribute to the total column, which are scaled by the factors $\lambda_{1}^{i}, \lambda_{2}^{i}$, respectively. The same is used to describe the CO column measured by IASI at night but without the mixing layer term.

$$
\begin{aligned}
\mathbf{T C}_{\text {IASI }}^{\text {day }} & =\sum_{i}^{N_{\text {Gridpoints }}}\left(\delta_{\text {footprint }}(i) \frac{\mathrm{AB}}{N_{\text {footprint }}} \hat{\lambda}_{1}^{i}\right. \\
& \left.+\delta_{\text {footprint }}(i) \frac{\mathrm{AM}}{N_{\text {footprint }}} \hat{\lambda}_{2}^{i}\right)+\boldsymbol{\epsilon} \\
\mathbf{T C}_{\text {IASI }}^{\text {night }} & =\sum_{i}^{N_{\text {Gridpoints }}}\left(\delta_{\text {footprint }}(i) \frac{\mathrm{AB}}{N_{\text {footprint }}} \hat{\lambda}_{1}^{i}\right)+\boldsymbol{\epsilon}
\end{aligned}
$$

Dropping the mixing layer term is motivated by the assumption that in the afternoon the thermal inversion defining a single mixing layer disappears and a cleaning process is favored by the the increased ventilation. A residual layer of $\mathrm{CO}$ will remain which contributes to the background $\mathrm{CO}$ amount in the retrieval. Independently, whether there is a mixing layer at night near the ground or not, the averaging kernel of the nightly CO column measurements of IASI shows almost negligible sensitivities near the surface and a term $\mathrm{AM}_{\text {night }}$ would be negligible as well. This can be seen in the averaging kernels in Pommier et al. (2010) and George et al. (2009); Turquety et al. (2009) showed in a day night comparison that megacities are only visible as $\mathrm{CO}$ hotspots from the daytime measurements.

Equations (7) and (8) illustrate the forward model which explains the measured columns as function of the averaged $\mathrm{CO}$ distribution. Each weighting function $\left(\mathbf{K}^{j}\right)$ belongs to measurements $\mathrm{TC}^{j}$, which are separated by daytime (Eq. 9) and nightime measurements (Eq. 10) as follows:

$$
\begin{aligned}
\mathbf{K}^{j} & =\frac{\left(\delta_{j}(1) \mathrm{AB}, \delta_{j}(2) \mathrm{AB}, \ldots, \delta_{j}(1) \mathrm{AM}, \delta_{j}(2) \mathrm{AM}, \ldots\right)}{N_{\text {footprint }(j)}} \\
\mathbf{K}^{j} & =\frac{\mathrm{AB}\left(\delta_{j}(1), \delta_{j}(2), \ldots \ldots, 0,0, \ldots\right)}{N_{\text {footprint }(j)}} .
\end{aligned}
$$

The functions $\delta_{j}(i)$ are used to evaluate if the CO column $(j)$ $\left(\mathrm{TC}^{j}\right)$ measured by IASI contains information about the $i^{\text {th }}$ grid point.

$\delta_{j}(i)=\left\{\begin{array}{ll}1 \text { if grid point (i) in field of view }(\mathrm{j}) \\ 0 & \text { else }\end{array}\right\}$

\subsubsection{Annual mean CO distribution: inversion}

The forward model tries to explain all measured columns by a single independent $\boldsymbol{x}$, the horizontal distribution of $\lambda_{1}$ and $\lambda_{2}$ while the dimension of $\boldsymbol{x}$ depends on the grid which is used. The inversion of the problem is ill-posed and since it uses a fine grid of $30 \times 30$ points in a $1^{\circ}$ latitude $\times 1^{\circ}$ longitude area, a regulation is necessary. The distribution of the background $\mathrm{CO}$ and the mixing layer $\mathrm{CO}$ is constrained independently and by by an empirically adjusted regularization strength.

The solution minimizes the penalty function (Pf), which consists of two parts regarding how well the measurements can be explained and how consistent the solution is with the a priori information in general or its shape. The measurement noise matrix $\mathbf{S}_{e}$, that describes the weighting of the fit of the forward simulation (Rodgers, 2000) is set to the identity matrix $\left(\mathbf{S}_{e}=\mathbf{1}\right)$ and dropped in the further description.

$$
\mathrm{Pf}=\left|\mathrm{TC}^{\mathrm{IASI}}-\mathbf{K} \cdot \boldsymbol{x}\left(\boldsymbol{\lambda}_{1}, \boldsymbol{\lambda}_{2}\right)\right|^{2}+\left(\boldsymbol{x}^{t} \mathbf{R}\left(\alpha_{\mathrm{bkg}}, \alpha_{\mathrm{ml}}\right) \boldsymbol{x}\right)
$$

The constraint is applied in the matrix $\mathbf{R}$ which consists of two blocks for the background and the mixing layer columns of average CO. No correlation between both quantities are introduced through the regularization (von Clarmann and Grabowski, 2007).

A diagonal matrix constrains the background layer, avoiding problems arising when the background $\mathrm{CO}$ column differs strongly from the a priori $\mathrm{CO}$ background distribution $\left(\lambda_{1}\right)$. A $L_{1}$-Tihkonov (Steck, 2002) smoothness constraint is used for the regularization of the horizontal $\mathrm{CO}$ distribution in the mixing layer column $\left(\lambda_{2}\right)$.

The optimization of the constraints is a critical task for the top-down $\mathrm{CO}$ emission estimation and the final choice is a result of various sensitivity studies. Two main error sources for the top-down estimation have been identified and should be avoided:

(a) A weak constraint leads to more positive and negative anomalies, triggered by random errors in the column measurements of IASI and by the spatial randomly distributed inhomogeneities due to IASI sampling during extreme events in traffic, abnormal ventilation, different annual seasons and fire events. The frequency of the triggered anomalies are not random but depend on the precision of IASI, the real day to day variance and the number of measurements per area. Their effect on the top-down emission estimation is not cancelled but it increases the estimated emission in case of positive anomalies that are identified as part of the urban pollution but the negative ones are ignored as elevated topography.

Therefore, a slightly over-constrained retrieval is chosen which does not go to the limit of the horizontal resolution which could be archived, but ensures that the resulting MCMA CO-footprint is a connected and smoothed area, Fig. 6.

(b) The $\mathrm{CO}$ content in the mixing layer is only constrained by a smoothness constraint. Any possible systematic over- or underestimation of the $\mathrm{CO}$ content in the MCMA is evaluated by the total content averaging kernel for $\mathrm{CO}$ distribution (A) (see Supplement). 


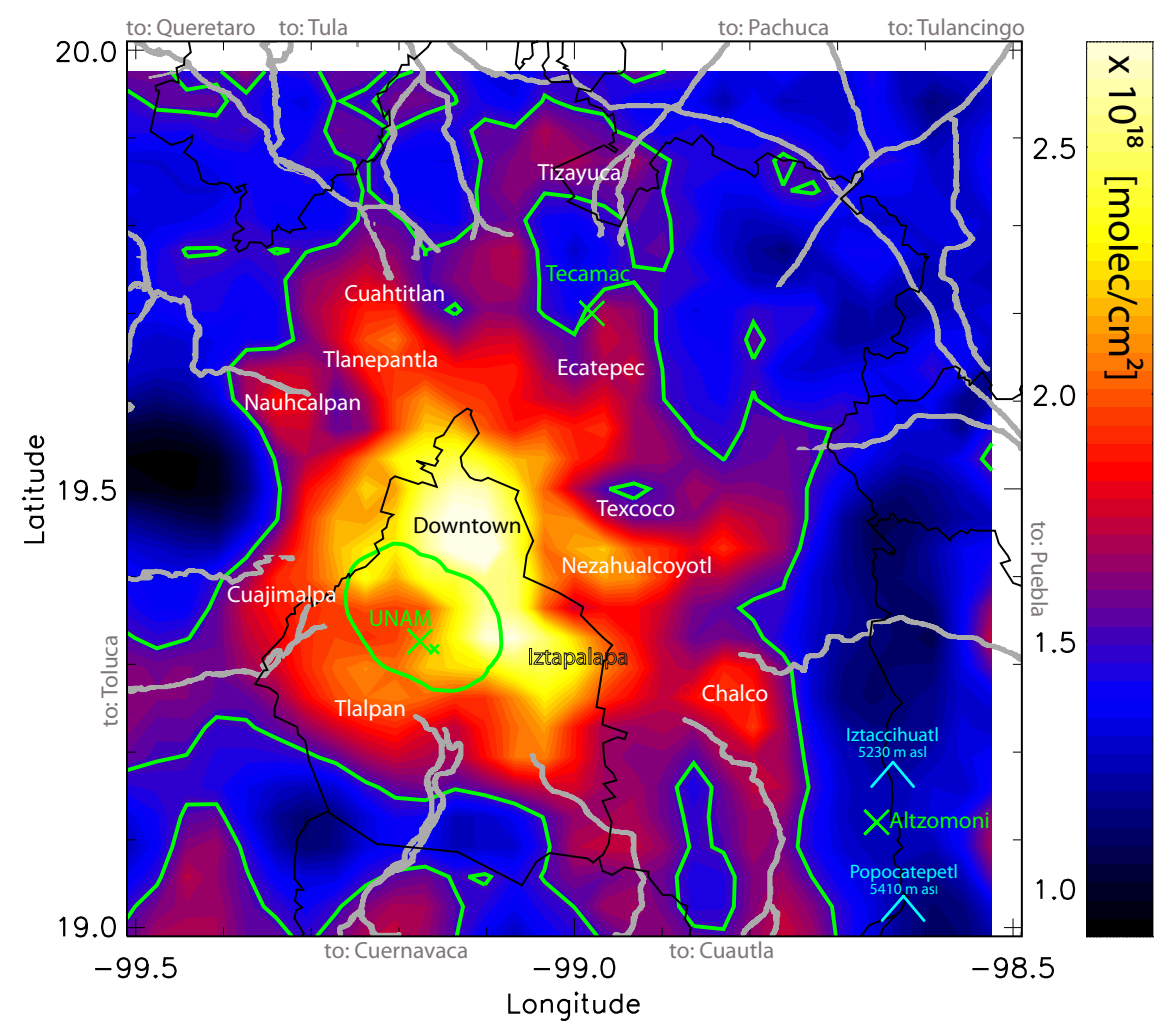

Fig. 6. Average $\mathrm{CO}$ column distribution for the morning overpass of MetOp-A in the Mexico basin reconstructed from the IASI data between 2007-2010. The locations of the ground based measurements are indicated by the large green crosses. The NCAR measurements during the MILAGRO campaign (March 2006) were taken at the university of Tecamac and the UNAM-measurements (2007-2009) at the UNAM Campus. The inner green contour-line is drawn around UNAM and indicates the area which contains $95 \%$ of the CO amount measured later around noon at UNAM. The outer green contour-line indicates the $1.51 \times 10^{18}$ molec cm $^{-2}$ level and defines the Mexico City Metropolitan Area (MCMA) in this work. (A small cross near UNAM, indicates where the line of sight between the UNAM-instrument and the sun passes through the upper part of the boundary layer during the morning overpass of IASI and illustrates that inhomogeneity might affect the conversion from slant to vertical columns.)

\subsubsection{Diagnostics and errors}

The reconstruction of the mean $\mathrm{CO}$ distribution is done with the optimal-estimation theory and allows us to apply all subsequent diagnostic, characterisation and error analysis (Rodgers, 2000). The averaging kernel (A) for the CO distribution is calculated $\left(\mathbf{S}_{e}=\mathbf{1}\right)$ by

$\mathbf{A}=\left(\mathbf{K}^{\mathrm{T}} \mathbf{K}+\mathbf{R}\right)^{-1} \mathbf{K}^{\mathrm{T}} \mathbf{K}$.

This diagostic tool allows to quantify the resolution, as commonly done in profile retrievals for example Funke et al. (2009) or recently applied by Krueger et al. (2013) in a similar context. The spatial resolution of the presented map is found to be $7 \mathrm{~km}$ in the center of Mexico City and slightly larger in more rural areas. The resolution helps to evaluate how the borders of the MCMA are smoothed by the datatreatment in addition to true change from urban to rual areas.

A total or MCMA content averaging kernel for the $\mathrm{CO}$ distribution is calculated analogously to the total or partial column averaging kernel for profiles. Therefore, the operator for the total content of the MCMA $\boldsymbol{g}_{\text {MCMA }}^{\mathrm{T}}$ is defined according to Rodgers and Connor (2003).

$\mathbf{A}_{\mathrm{MCMA}}=\boldsymbol{g}_{\mathrm{MCMA}}^{\mathrm{T}} \mathbf{A}$

In this study, we iteratively optimized the constraints aiming among other criteria to shape the "total content averaging kernel for $\mathrm{CO}$ distribution in the MCMA" and maximized the information about the CO content in the MCMA. This means that the $\mathrm{CO}$ anomaly inside the MCMA is well detected and correctly quantified, while the $\mathrm{CO}$ anomaly outside the MCMA is likely ignored (the resulting "total content averaging kernel for CO distribution amount in the MCMA" can be found in the Supplement).

Sensitivity to measurement noise is described through the so called contribution or gain matrix $\left(\mathbf{D}:=\left(\mathbf{K}^{\mathrm{T}} \mathbf{K}+\mathbf{R}\right)^{-1} \mathbf{K}^{\mathrm{T}}\right)$ and for the content of the MCMA $\mathbf{D}_{\mathrm{MCMA}}:=\boldsymbol{g}_{\mathrm{MCMA}}^{\mathrm{T}} \cdot \mathbf{D}$.

The statistical smoothing and measurement error according to Rodgers (2000) can only be quantified, if a covariance matrix for the possible CO-mean distributions and a covariance for measurement noise and day to day variance in the 
$\mathrm{CO}$ distribution is available. The first of those matrices can principally be estimated from an ensemble of chemical transport model studies using different inventories. The latter can be estimated by a single model run of a longer period and from the characteristics of the IASI measurements. Including model studies is out of the scope of this work and the smoothing and measurement errors are not quantified here.

A "resulting" error is estimated by the comparison of the results for different constraints, one being slightly overconstrained and another slightly under-constrained. The uncertainty (result constraint $1_{-}$result $_{\text {constraint } 2} \approx 15 \%$ ) observed here has contribution from both the smoothing error and measurement noise error and reflects a rough evaluation of the error and the sensitivity to the regularization strength (more detailed discussion on the errors are presented in the Supplement).

\subsection{Top-down estimation for annual $\mathrm{CO}$ emission in MCMA}

This section presents the top-down emission estimation combining the information provided by the prior sections. As described earlier, the vertical total column of a pollutant can change due to emission, advection, chemistry and/or deposition, Eq. (1). For CO, on the time scale of hours, chemical degradation or sedimentation do not play a role and by selecting days on which advection is low, the changes observed in the column is dominated by the emissions near the surface. A statistically significant growth-rate as calculated in Sect. 2.2 with the appropriate criteria, reflects the emission directly. In Sect. 3, this local growth-rate is directly compared with bottom-up emission values properly treated with a propagation kernel for spatial representativeness, as well as with the total columns measured from IASI.

\subsubsection{Extrapolation to the entire MCMA}

For an estimation of the overall $\mathrm{CO}$ emission, the emission per unit area near UNAM campus has to be extrapolated to the effective area of the Mexico City Metropolitan Area. There are two different information sources about spatial distributions of $\mathrm{CO}$, the official bottom-up inventory and the spatial distribution of $\mathrm{CO}$ column reconstructed from IASI measurements (Sect. 2.3). Both information sources could be used to extrapolate the emission flux around UNAM to the entire MCMA, but the critical question is for which area in those distributions the measurement at UNAM is representative. If the inventory is used, a kind of "averaging kernel for surface emission" ( $\mathrm{AKE}_{\mathrm{UNAM}}^{\text {surface }}$ ) is necessary because the inventory provides a map of surface emission (tons per year), and each molecule found at some altitude in the column is released somewhere at the ground. There are different strategies to estimate the footprint, $\mathrm{AKE}_{\mathrm{UNAM}}^{\text {surface }}$. Model based footprints have been used for single measurements and small scales flux on tower measurements by Velasco et al. (2009).
Geibel et al. (2010) used recently a footprint based on a full year average to explain the $\mathrm{CO}$ column measurements on Ascension Island.

Otherwise, if a distribution of the total CO column is available as in our case, the representative location would be the exact coincident point both of the ground and satellite measurements. However, a direct comparison may be done only if the ground and the satellite measurements would be taken at the same time of the day. Unfortunately, there is about a $2 \mathrm{~h}$ difference between the IASI overpass and the time interval in which the growth-rate is determined from the ground measurement. Therefore, the propagation of the $\mathrm{CO}$ in the time between IASI overpass and the ground based measurements (11:15-13:15 LT) has to be determined quantitatively. In this case of considering the vertical column of $\mathrm{CO}$ only horizontal displacement of the air has to be taken into account. Therefore, the average wind velocity of the mixing layer has to be known at 10:00-11:00 LT. Despite that only the wind velocity at surface is measured regularly, wind profiles taken during MILAGRO in 2006 (de Foy et al., 2008) indicate that the mean wind velocity at the ground (here taken as the average of 6 stations) can be used as a representative value of the whole wind velocity of the strong convective mixing layer.

As a second step, the fresh $\mathrm{CO}$ has to be separated from the background values from the area outside the MCMA as defined in Sect. 2.3. The background $\mathrm{CO}$ is estimated to be $1.51 \times 10^{18}$ molec $\mathrm{cm}^{-2}$ according to the description in Sect. 2.1. The integration of the fresh $\mathrm{CO}\left(\mathrm{TC}_{\mathrm{IASI}}-1.51 \times\right.$ $10^{18} \mathrm{molec}^{-2}$ ) is performed over the area where $\mathrm{TC}_{\text {IASI }}$ is greater than the background. The division of the integrated mixing layer CO MCMA content by the mixing layer column at UNAM $\left(\mathrm{TC}_{\text {UNAM }}^{10: 19}-1.51 \times 10^{18}\right.$ molec $\left.^{-2}\right)$ results in an effective area $\mathrm{A}_{\text {eff }}$, Eq. (15). The value for $\mathrm{TC}_{\mathrm{UNAM}}^{10: 19}$ is the total column measured by IASI over UNAM which is basically the same as the column measured from the ground at UNAM backward extrapolated to 10:19LT, Sect. 3 .

$\mathrm{A}_{\mathrm{eff}}=\frac{\int_{\mathrm{MCMA}}\left(\mathrm{TC}_{\mathrm{IASI}}-1.5 \times 10^{18} \mathrm{~cm}^{-2}\right) \mathrm{dA}}{\left(\mathrm{TC}_{\mathrm{UNAM}}^{10: 19}-1.5 \times 10^{18} \mathrm{~cm}^{-2}\right)}$

The effective area can be thought of as an extrapolation factor used to convert a local emission flux to the entire area of interest. A value of $1832.6 \mathrm{~km}^{2}$ is found for $A_{\text {eff }}$ in the MCMA, but this does not reflect a real area as it is weighted with its $\mathrm{CO}$ column. The real area included in the $1.51 \times 10^{18}$ molec cm ${ }^{-2}$ contour line in Fig. 6 is $5177 \mathrm{~km}^{2}$. The extrapolation factor $\mathrm{A}_{\text {eff }}$ is 2.8 times smaller than the real area as the measurement site UNAM is located near the center of MCMA, a favourable condition. The assumption of a homogeneous $\mathrm{CO}$ emission in the MCMA would result in an overestimation by a factor of 2.8 . 


\subsubsection{Temporal distribution of $\mathrm{CO}$ emissions}

The emission flux at UNAM, which can be now extrapolated to the entire MCMA, is valid only for the time around noon. It is important to know the temporal distribution of the $\mathrm{CO}$ emissions in order to extrapolate this value to the whole day. No direct "top-down" information is available for the temporal distribution since the column growth-rate and the spatial distribution are obtained at distinct and varied times from the ground-based measurements and the IASI overpass time. However, there is very valuable information on the diurnal distribution of the $\mathrm{CO}$ emissions from the official inventory shown in Fig. 2, which reports spatially and temporally resolved emission fluxes (SMA-GDF, 2010a). The evolution of the emissions depend on traffic and are obtained by vehicle counts at different parts of the city. From this distribution the emission per day is roughly 18.5 times the emission per hour at noon.

To determine an error estimation of this factor, we modelled the temporal distribution at various times using simple distributions. Each distribution is an estimate of a particular scenario e.g. a uniform distribution, less emission during night than during day, etc. To see how sensitive the temporal extrapolation factor depends on the distribution, 8 very simple distributions were studied: 2 boxcar, 2 triangle, 3 trapezoid distributions and the distribution from the official inventory. Each distribution has a corresponding temporal extrapolation factor of $24,20,12,10,22,20,19$ and $18.5 \mathrm{hday}^{-1}$, respectively. From this ensemble the average (AVG) of $18.2 \mathrm{hday}^{-1}$, standard deviation (STD) of $26 \% \times \mathrm{AVG}$ and the standard error $\frac{\mathrm{STD} / \mathrm{AVG}}{\sqrt{N-1}}$ of $\approx 10 \%$ are calculated and indicates that an $\approx 10 \%$ error rises from the extrapolation using the distribution of the $\mathrm{CO}$ emissions in Fig. 2.

\section{Comparison and validation}

In this section we compare the results from the groundbased with the satellite measurements (Sects. 3.1 and 3.2). In Sect. 3.2 the results from the top-down emission estimation is compared with the bottom-up. The first validation proves a reliability and consistency of the column retrievals and that the concept using Averaging Kernels together with local information about the atmospheric structure works well. Section 3.3 illustrates how the same results have to be compared to the bottom-up emissions inventory and for which area the flux measurements at UNAM are representative. More technical details regarding this subject can be found in the supplement.

\subsection{Comparison with mean and coincident IASI values}

Even though the absolute values from IASI are not critical for estimating the emission in the MCMA as presented here, a detailed comparison of both mean values and coincident values using selected criteria are presented in the Supplement. As expected, a better agreement is obtained when the mean total columns of $\mathrm{CO}$ measured outside the MCMA are compared from all ground-based (Tecámac) and satellite (IASI) measurements: $1.65 \times 10^{18}$ molec cm $^{-2}$ vs. $1.72 \times 10^{18}$ molec cm $^{-2}$. The large temporal and spatial variability within the city results in mean values at UNAM that differ by more than $20 \%$ when compared to the mean of all IASI values within the wide MCMA. The comparison is then made for individual measurements which coincide both in time and space (15 min and $30 \mathrm{~km}$ radii) and using both a corrected IASI column, and the degraded ground-based column using IASI's averaging kernels (worse sensitivity near the surface). Here the agreement is much better although the results are disperse among the different criteria chosen and no systematic bias can be established due to the reasons presented in that section.

\subsection{Validation using displaced air masses}

Another strategy motivated by the large inhomogeneity of $\mathrm{CO}$ within the city and the temporal difference between the IASI overflight time and the ground-based measurements, is presented in the supplement. Using information about the averaged wind data, a footprint is reconstructed which defines the area where the CO measured by IASI at 10:19 LT (IASI's overflight time), has been prior to reaching UNAM at noon. At the same time, the growth-rate determined at noon can be back extrapolated to 10:19LT in order to know which average column is expected over UNAM. These "virtual" column amounts, $(2.38 \pm 0.084)$ and $(2.39 \pm 0.12) \times 10^{18}$ molec cm $^{-2}$, respectively, are consistent and prove the usefulness of calculating a wind propagation operator which accounts for displaced air masses. The details of how this "footprint" is calculated are presented in the Supplement.

\subsection{Comparison of emission results with bottom-up values}

The official inventory for 2008 (SMA-GDF, 2010a) reports spatially resolved emissions fluxes and also its temporal dependence, so that the growth-rate ( $\equiv$ emission flux) measured at UNAM around 12:00 LT can be compared without introducing added uncertainty to the measurements. Such a comparison has to be done with care, as it is not evident which area is represented by the growth-rate measured at UNAM. Similar to the method described for validating $\mathrm{CO}$ columns from ground-based and satellite measurements (see Supplement), a propagation kernel for surface emission $\mathrm{AKE}^{\text {surface }}$ has to be estimated.

The estimation and construction of $\mathrm{AKE}^{\text {surface }}$ takes into account that the air masses of different altitudes in the mixing layer might correspond to different times and different areas. The footprint $\mathrm{AKE}_{\mathrm{UNAM}}^{\mathrm{surface}}$ is calculated in a similar way as the 
propagation kernel $\left(\mathbf{G}_{t_{\mathrm{UNAM}}, t_{\mathrm{UNAM}}-t^{\prime}}^{\mathrm{TC}}\right)$ in the Supplement:

$\operatorname{AKE}_{\mathrm{UNAM}}^{\text {surface }}($ lat, lon $)=\frac{\int_{0}^{t_{\max }} \mathbf{G}_{t_{\mathrm{UNAM}}, t_{\mathrm{UNAM}}-t^{\prime}}^{\mathrm{TC}}(\text { lat, lon }) \cdot \mathrm{d} t^{\prime}}{t_{\max }}$

The growing mixing layer column consists of parts with different ages, even if they are well mixed. The mixing layer growth-rate and its altitude $(\approx 1 \mathrm{~km}$ per hour and $\approx 3 \mathrm{~km}$ at 11:00 LT) could indicate the mean vertical movement of the $\mathrm{CO}$ molecules. We estimate the travel-time $\left(t_{\max } \approx 3 \mathrm{~h}\right)$ of the upper $\mathrm{CO}$ molecules emitted earlier at surface with the following equation.

$t_{\max }=\mathrm{MLH} \cdot\left(\frac{\mathrm{dMLH}}{\mathrm{d} t}\right)^{-1}$

For a comparison of the flux calculated from the growth-rate (this study) and the surface emission fluxes of the official inventory for 2008 (SMA-GDF, 2010a) we use the following propagation kernel for surface emission $\left(\mathrm{AKE}_{\mathrm{UNAM}}^{\text {surface}}\right)$ based on four terms:

$\mathrm{AKE}_{\mathrm{UNAM}}^{\text {surface }} \approx \frac{\mathbf{G}_{12,8}^{\mathrm{TC}}+\mathbf{G}_{12,9}^{\mathrm{TC}}+\mathbf{G}_{12,10}^{\mathrm{TC}}+\mathbf{G}_{12,11}^{\mathrm{TC}}}{4}$

$E_{\mathrm{Bottom}-\mathrm{up}}^{\mathrm{UNAM}}=\frac{\mathrm{yr} \mathrm{h}^{-1}}{365 \cdot 18.5} \cdot \int \mathrm{AKE}_{\mathrm{UNAM}}^{\mathrm{surface}} \cdot E_{\mathrm{bottom}-\text { up }}^{\mathrm{MCMA}} \mathrm{dlat} \cdot \mathrm{dlon}$

The result is that the emission flux from the official inventory which is representative for the area around UNAM is $292 \mathrm{~kg} \mathrm{~km}^{-2} \mathrm{~h}^{-1}$, which is $\approx 30 \%$ higher than $(174 \pm$ 20) $\mathrm{kg} \mathrm{km}^{-2} \mathrm{~h}^{-1}$ estimated by the top-down method presented in this work.

\section{Results and discussion}

\subsection{Carbon monoxide emission around the UNAM campus}

It has already been presented that an averaged emission flux from all ground-based measurements falling within a certain criteria (time interval, wind conditions), can be calculated. The value of $(174 \pm 20) \mathrm{kg} \mathrm{km}^{-2} \mathrm{~h}^{-1}$ shown in Fig. 5c is the result obtained from a large dataset measured between 2007 and 2009. CO column measurements taken during two consecutive days are shown in Fig. 5a,b. These days are chosen as an example since they presented similar wind conditions (wind direction $\mathrm{WD}=\mathrm{NE}$, wind speed $\mathrm{WS} \approx 0.7 \mathrm{~m} \mathrm{~s}^{-1}$ at $11: 00$ ) but very different growth-rates (slopes marked in Fig. 5a, b). The converted emission fluxes of $(105 \pm 13) \mathrm{kg} \mathrm{km}^{-2} \mathrm{~h}^{-1}$ and $(309 \pm 25) \mathrm{kg} \mathrm{km}^{-2} \mathrm{~h}^{-1}$ measured on 20 and 21 January 2008, correspond to a Sunday and Monday, respectively (errors resulting from the $95 \%$ confidence interval).

The difference between Monday and Sunday is rather large as expected from traffic patterns and their emission fluxes might represent typical values. The data shows that
Table 2. Comparison of $\mathrm{CO}$ emission estimates for the Mexico City Metropolitan Area.

\begin{tabular}{lll}
\hline Method & Top-Down & Bottom-Up \\
\hline Emission: & This work & Official Inventory \\
Date & $\approx 2008-2009$ & 2008 \\
12:00 UNAM (flux) & $174 \pm 20 \mathrm{~kg} /\left(\mathrm{km}^{2} \mathrm{~h}\right)^{\mathrm{a}}$ & $295 \mathrm{~kg} /\left(\mathrm{km}^{2} \mathrm{~h}\right)^{\mathrm{b}}$ \\
11-12 in MCMA & $319 \pm 72 \mathrm{tons} \mathrm{h}^{-1}$ & $234 \mathrm{tons} \mathrm{h}^{-1}$ \\
daily in MCMA & $5.90 \pm 1.46 \mathrm{Gg} \mathrm{day}^{-1}$ & $4.28 \mathrm{Gg} \mathrm{day}^{-1}$ \\
annual in MCMA & $2.15 \pm 0.53 \mathrm{Tg} \mathrm{yr}^{-1}$ & $1.57 \mathrm{Tg} \mathrm{yr}^{-1}$ \\
\hline
\end{tabular}

a Only the statistical error resulting from the column growth-rate is taken into account. ${ }^{b}$ Value using the footprint estimated from wind data (SMA-GDF network), drawn in Fig. 6 as a green circle around UNAM.

a Sunday might have $\approx 1 / 3$ less CO (Stremme et al., 2009), an estimation which is higher than what can be deduced from the official inventory, but the emissions from the $\mathrm{CO}$ column measurements are based on a restricted daytime. The pair of days illustrate, however, that the column growth-rate is dominated by the surface emission.

\subsection{Annual emission of the entire MCMA}

The mean column growth-rate measured at UNAM represents a weighted average of the emission flux centred within the Mexico City Metropolitan Area. It can be extrapolated to the entire metropolitan area using the retrieved CO column distribution from the satellite at around 10:19 LT as described in Sect. 2.4. A background value from measurements outside the MCMA at Tecámac serves to define the lower border of this CO-weighted area. From these three datasets together with some assumptions of the temporal distribution, the total emission of the megacity is estimated to be $(2.15 \pm 0.5) \mathrm{Tg} \mathrm{yr}^{-1}, 37 \%$ higher than the emission reported by the official inventory for the year 2008. The results are summarized in Table 2.

\subsection{Errors}

An error analysis in remote sensing has to focus on different kinds of errors and is a challenging task. Here we have a combination of factors affecting the uncertainty: wind distribution, diurnal cycle of traffic, CO retrieval of 3 different instruments, determination of background level, calculation of the growth-rate and determination of the horizontal distribution of the CO column. All components for the emission estimation are calculated differently so that their errors and error contributions must be evaluated individually: (a) the error of the emission flux at UNAM (the growth-rate) is obtained from the $95 \%$ confidence interval of the fitted slope, (b) the standard error evaluates the reliability of the temporal distribution and the resulting extrapolation factor, (c) the difference of two regularizations is used to estimate an error due to the reconstruction of the spatial CO distribution, (d) the errors of the propagation (footprint) is calculated according to a 
Table 3. Summary of errors for the total CO emission estimation in the MCMA.

\begin{tabular}{|c|c|c|c|c|c|}
\hline \multicolumn{2}{|l|}{ Error source } & \multicolumn{3}{|c|}{ Error on $\mathrm{CO}$ emissions } & \multirow[t]{2}{*}{ Method of estimation } \\
\hline $\begin{array}{l}\text { Parameter: } \\
\text { Emission flux at UNAM: }\end{array}$ & $\%$ & $\mathrm{Tg} \mathrm{yr}^{-1}$ & $\%$ & type & \\
\hline Column growthrate: & 11.5 & 0.25 & 11.5 & random ${ }^{b}$ & $95 \%$-confidence interval \\
\hline $\begin{array}{l}\text { Advection col.: } \\
\text { Spatial extrapolation: }\end{array}$ & - & $0.1-0.2$ & $<5-10 \%$ & systematic & Footprint 11:00, 12:00, 13:00 \\
\hline IASI distribution (empirical) & - & 0.3 & 15 & random ${ }^{b}$ & different constraints \\
\hline Smoothing error (horizontal) & - & -0.0017 & -0.08 & systematic & $\left(\mathbf{A}_{\text {IASI }}-\boldsymbol{g}^{t}\right) x_{\text {official }}$ \\
\hline $\begin{array}{l}\text { IASI distrib. (Rodgers, 1990) } \\
\text { Background Level: }\end{array}$ & $20 \%$ & 0.17 & 8 & random $^{\mathrm{a}}$ & $\sqrt{g^{t} \cdot \mathbf{D} \cdot \mathbf{S}_{y} \cdot \mathbf{D} \cdot \boldsymbol{g}}$ \\
\hline Measurements Tecamac & 3.5 & 0.27 & 12.5 & random ${ }^{b}$ & $\begin{array}{c}\text { Effect of precision on } \\
\text { estimation of lower border }\end{array}$ \\
\hline Seasonality & $\approx 10 \%$ & $<0.37$ & $<17.8$ & systematic & $\mathrm{CO}_{\text {May }}^{\text {TECAMAC }}=\left(1+\frac{10 \%}{2}\right) \mathrm{CO}_{\text {avgr. }}^{\text {TECAMAC }}$ \\
\hline $\begin{array}{l}\text { Temporal extrapolation: } \\
\text { From hour to day }\end{array}$ & & $\approx 0.2$ & $\approx 10$ & random $^{b}$ & $\begin{array}{l}\text { Error from different distributions } \\
\text { (triangle, boxcar, trapeze, official) }\end{array}$ \\
\hline From Day to Year & & $<0.20$ & $<9.5$ & systematic & $\begin{array}{l}\text { No weekend versus } \frac{2}{3} \text { emission } \\
\text { on Sunday (Stremme et al., 2009) }\end{array}$ \\
\hline From Day to Year & & 0.01 & \pm 0.5 & systematic & $\begin{array}{l}\text { No weekend versus official weekend } \\
\text { effect (Official Inventory for 2008) }\end{array}$ \\
\hline Total uncertainty: & - & 0.53 & 24.8 & random $^{b}$ & $\begin{array}{l}\text { sqrt. of sum of the square } \\
\text { of independent } \\
\text { random errors marked by b }\end{array}$ \\
\hline
\end{tabular}

a The error calculated according to Rodgers (1990) is not included in the total error. The random error estimated by the difference of the results using different retrieval settings and constraints includes also components of this error.

$\mathrm{b}$ The random error which is taken into account to the total random error.

$10 \%$ change in the wind speed from surface to mixing layer height (a typical value for unstable conditions), and (e) the error resulting from the background level is obtained from a sensitivity study and the estimated precision of the measurement at Tecámac.

A total error can then be estimated from the following independent errors also summarized in Table 3:

1. growth-rate: $11.5 \%$

2. temporal distribution: $10 \%$

3. CO distribution: $15 \%$

4. footprint: $10 \%$

5. background level: $12.5 \%$

The background column of CO in the Mexico Valley is occasionally influenced by biomass burning (Yokelson et al., 2007; Crounse et al., 2009). Such anomalies due to biomass burning should not significantly affect the mean of the column growth-rate at UNAM or the mean CO distribution reconstructed from IASI data, but they might slightly degrade the confidence interval of the growth-rate and the precision of the mean $\mathrm{CO}$ distribution. The presence of biomass burning might have elevated the background of $\mathrm{CO}$ during the measurement at Técamac (March 2006). A slight overestimation
Table 4. Insitu measurements of CO. Five sites of the air quality monitoring network (RAMA) are used to determine the mean CO surface concentration at UNAM.

\begin{tabular}{lccc}
\hline Acronym & Name & latitude & longitude \\
\hline PED & Pedregal & $19.325^{\circ} \mathrm{N}$ & $99.204^{\circ} \mathrm{W}$ \\
PLA & Plateros & $19.367^{\circ} \mathrm{N}$ & $99.200^{\circ} \mathrm{W}$ \\
SUR & Santa Ursula & $19.314^{\circ} \mathrm{N}$ & $99.150^{\circ} \mathrm{W}$ \\
TAX & Taxqueñna & $19.337^{\circ} \mathrm{N}$ & $99.123^{\circ} \mathrm{W}$ \\
UIZ & UAM Iztapalapa & $19.362^{\circ} \mathrm{N}$ & $99.071^{\circ} \mathrm{W}$ \\
\hline
\end{tabular}

of the columnar $\mathrm{CO}$ background results in a slight underestimation of the total CO emission in the MCMA. However according to Crounse et al. (2009) biomass burning has almost negligible impact on the air quality in the MCMA and Yokelson et al. (2007) showed that most hot spots and fires registered by space and air borne measurements were located in the mountains south of Mexico City and therefore without relevance to the measurements in Técamac. 


\section{Summary and conclusions}

In this contribution, a new and valuable methodology is presented for estimating carbon monoxide emissions on large urban areas based on a top-down approach, which uses mainly remote sensing observations. The key components for calculating the annual emissions for the entire metropolitan area of Mexico City were: (1) Determination of the CO column growth-rate under low ventilation conditions, and during a reliable time interval to prevent contamination from inhomogeneity (11:15-13:15 LT). Solar absorption FTIR measurements taken during a large number of days (622) between 2007 and 2009 ensured statistical significance in the locally derived emission flux of $(174 \pm 20) \mathrm{kg} \mathrm{km}^{-2} \mathrm{~h}^{-1}$ measured over the UNAM campus. (2) Reconstruction of a spatial distribution of the CO columns throughout the MCMA with a horizontal resolution better than $10 \mathrm{~km}$ in the center of MCMA. Data from the IASI instrument for the same years were used and an algorithm was developed which weights every overpass together with the additional information of the mixing layer height into a fine grid to obtain a sensitivity corrected, smoothed and highly resolved distribution of the annual averaged CO. (3) Extrapolation of the locally derived emission flux corresponding to the time of the satellite overflight time onto the entire metropolitan area. (4) Temporal extrapolation of the result from the measurement time around noon to $24 \mathrm{~h}$ using an average diurnal emission pattern and then to the whole year.

The annual emission resulting from this top-down estimation was found to be of $2.15 \pm 0.53 \mathrm{Tg}$. In the official inventory of 2008 (SMA-GDF, 2010a), an emission of $1.57 \mathrm{Tg}$ is reported for the entire MCMA. The difference of $-0.58 \mathrm{Tg}$ is just above the uncertainty in the value presented here, which indicates that the bottom-up estimation might be underestimated. It could be of more significance to point out, however, that when the locally derived emissions around UNAM are compared (see Table 2), a significantly larger flux (70\%) from the bottom-up approach than the one derived from the column growth-rate measurements can be detected. This indicates that the spatial distribution used in the emissions inventory might be much more inaccurate than the absolute amount reported for the entire region. This leads us to the conclusion that the $\mathrm{CO}$ distribution presented in Fig. 6, although it reflects the situation in the morning hours, represents the best approximation we have to date for the spatial distribution of the emissions of this pollutant.

According to Yurganov et al. (2011), strong source areas like megacities seem to be a problem which is not completely understood and new aspects in satellite validation using these sites have to be discussed. Ground-based total column measurements in and at the edge of large urban areas are scarce but crucial to evaluate nadir sounders. From the reconstructed column distribution around the MCMA, excellent agreement is found in the comparison of IASI-FORLI with the ground-based measurements. Based on a strategy to correct for time-displaced air masses using average wind data and a constructed footprint (see Supplement), both groundbased and satellite measurements present outstanding agreement. It can also be established that the IASI instrument provides data with exact pointing, since most features in and around the city (mountains, urban features, highways, etc.) can be identified.

The methodology used here can certainly be applied to other cities and regions of the world. The emissions of other pollutants, of course with different considerations and assumptions, could also be investigated and is the subject of future work. Given that most of the $\mathrm{CO}$ derives from cars, the total $\mathrm{CO}_{2}$ emission in the MCMA from the transport sector can be estimated if the average $\mathrm{CO}_{2} / \mathrm{CO}$ emission ratio is known. Using the $(2.15 \pm 0.5) \mathrm{Tg} \mathrm{yr}^{-1}$ of $\mathrm{CO}$ derived in this work and different $\mathrm{CO}_{2} / \mathrm{CO}$ mass ratios, the annual emission of $\mathrm{CO}_{2}$ can be estimated. We have derived a mass ratio of 14.8 based on measurements performed in 2001 from FTIR-measurements at UNAM (Grutter , 2003) $(R=0.52)$, a value far smaller than the $\mathrm{CO}_{2} / \mathrm{CO}$ mass ratio (143) recently derived for the urban area around Los Angeles, CA (USA) by Wunch et al. (2009) from solar absorption FTIR spectra taken between August 2007 and June 2008. From the 14.8 emission factor an overall emissions of $(32 \pm 7) \mathrm{Tg} \mathrm{yr}^{-1}$ is obtained for $\mathrm{CO}_{2}$. This emission lies between what is reported by the official inventory for the transport sector only $(22.3 \mathrm{Tg})$ and the total yearly emission of $\mathrm{CO}_{2}$ in the MCMA (44 Tg) for that year (SMA-GDF, 2010b). The emission factors are one of the most important sources of uncertainty and vary strongly for different cars, traffic and local conditions, especially since the ones we have used differ in time and location. Also, $\mathrm{CO}_{2}$ has a wider variety of sources and for a better estimation and specification of the emissions, one has to determine its own growth-rate and compare with a simultaneously measured $\mathrm{CO}_{2} / \mathrm{CO}$ mass ratio. Although work is already in progress, this simple exercise provides already a good and independent approximation.

The recent work of Gisi et al. (2012) shows that the same interferometer with resolution $0.5 \mathrm{~cm}^{-1}$ using improved solar tracking and components optimized for the near infrared region is capable to retrieve $\mathrm{CO}_{2}$ with high precision. A direct determination of anthropogenic $\mathrm{CO}_{2}$ emissions based on atmospheric measurements is desirable, planned and discussed in recent literature (Bovensmann et al., 2010; Velazco et al., 2011). Because of the atmospheric background, a topdown emission estimation for $\mathrm{CO}_{2}$ is far more difficult than for $\mathrm{CO}$, but for a sufficiently sensitive sensor the same approach would apply under special and periodic source conditions. A constellation of more satellites holding similar sensors passing at different times, as discussed in "Configuration 002" in Velazco et al. (2011), could allow for the determination of the column growth-rates of this and other gases globally. 
Appendix A

Acronyms and abbreviations.

\begin{tabular}{|c|c|}
\hline $\mathrm{AB}$ & sensitivity to a perturbation like a scaling of the background profile \\
\hline $\mathrm{AK}$ & averaging kernel \\
\hline $\mathrm{AKE}_{\mathrm{UNAM}}^{\text {surface }}$ & averaging kernel for CO surface emission around UNAM \\
\hline$A K P$ & averaging kernel (matrix) for profiles (molecules per layer) \\
\hline $\mathrm{AM}$ & sensitivity to a perturbation like pollution in the mixing layer \\
\hline A & averaging kernel (matrix) for $\mathrm{CO}$ distribution \\
\hline ACE-FTS & Atmospheric Chemistry Experiment - Fourier Transform Spectrometer \\
\hline CNES & Centre National d'Etudes Spatiales \\
\hline $\mathrm{CO}$ & carbon monoxide \\
\hline $\mathrm{CO}_{2}$ & carbon dioxide \\
\hline DOF & degree of freedom of signal (retrieval) \\
\hline$\delta_{\text {footprint }}(i), \delta_{\mathrm{j}}(i)$ & the Dirac-symbol describes if a point $i$ is inside the field of view of IASI ( $j$ ) \\
\hline$E_{\text {Bottom-up }}^{\text {UNAM }}$ & emission flux at UNAM estimated by the bottom-up inventory \\
\hline$\epsilon$ & deviation of CO column from mean value as seen by IASI + measurement noise error of IASI \\
\hline EUMETSAT & European Organisation for the Exploitation of Meteorological Satellites \\
\hline FOV & field of view of the IASI instrument \\
\hline FORLI & Fast Optimal/Operational Retrieval on Layers for IASI algorithm \\
\hline FTIR & Fourier Transform Infra Red Spectrometer \\
\hline FTS & Fourier Transform Spectrometer \\
\hline $\mathbf{G}_{12: 00,08: 00 / 09: 00 / 10: 00 / 11: 00}^{\mathrm{TC}}$ & propagation kernel which describes the displacement of the airmass between \\
\hline & 08:00/09:00/10:00/11:00 and 12:00 LT \\
\hline $\mathbf{G}_{t_{\mathrm{UNAM}}, \Delta t^{\prime}}^{\mathrm{TC}}$ & propagation kernel which describes the displacement of the airmass \\
\hline$g^{t_{\mathrm{UNAM}}^{\mathrm{T}}, \Delta t^{\prime}}$ & total content operator \\
\hline LMDz-INCA & a Chemistry-Transport Model \\
\hline$\lambda_{1}^{i}$ & background column amount of $\mathrm{CO}$ at grid point $\mathrm{i}$ \\
\hline$\lambda_{2}^{i}$ & mixing layer column amount of $\mathrm{CO}$ at grid point $\mathrm{i}$ \\
\hline Magna & $\begin{array}{l}\text { gasoline produced by the company PEMEX with an octane rating of } 87 \text { and a total sulfur } \\
\text { content of } 500 \mathrm{ppm}\end{array}$ \\
\hline MCMA & Mexico City Metropolitan Area \\
\hline MetOp-A & sattelite-plattform \\
\hline MILAGRO & Megacity Initative: Local and Global Research Observations \\
\hline MIRAGE & Megacities Impact on Regional and Global Environment \\
\hline MLH & mixing layer height \\
\hline MOPITT & Measurements Of Pollution In The Troposphere \\
\hline MOZAIC & Measurement of ozone, water vapour, carbon monoxide and nitrogen oxides by airbus in-service aircraft \\
\hline$\mu^{*}$ & $\operatorname{Exp}(\operatorname{avgr} .(\ln (x)))$, parameter to describe the median in a log-normal distribution \\
\hline $\boldsymbol{n}(\phi, \theta)$ & unit vector pointing in the direction $\phi, \theta$ \\
\hline NCAR & National Center for Atmospheric Research \\
\hline NCEP & National Centers for Environmental Prediction \\
\hline$N_{\text {footprint }}$ & number of gridpoints inside the field of view of the IASI measurement \\
\hline PEMEX & Petróleos Mexicanos (Mexican state-owned petroleum company) \\
\hline
\end{tabular}




\begin{tabular}{|c|c|}
\hline Premium & imported gasoline with higher octane rating than Magma \\
\hline $\operatorname{prf}_{1}^{\mathrm{VMR}}$ & linearly with height decreasing volume mixing ratio (VMR) profile \\
\hline $\operatorname{prf}_{2}^{\mathrm{VMR}}$ & boundary layer volume mixing ratio (VMR) profile \\
\hline $\operatorname{prf}_{1}$ & normalized background $\mathrm{CO}$ profile in molecules $\mathrm{cm}^{-1}$ per layer \\
\hline $\operatorname{prf}_{2}$ & normalized mixinglayer $\mathrm{CO}$ profile in molecules $\mathrm{cm}^{-1}$ per layer \\
\hline $\operatorname{prf}_{\mathrm{CO}}$ & average co profile for a grid point \\
\hline RAMA & monitoring network: Red Automática de Monitoreo Atmosférico \\
\hline REDMET & meteorological network: Red de Meteorología y Radiación Solar \\
\hline $\mathbf{R}$ & constraint matrix \\
\hline $\mathrm{SC}$ & slant total column of $\mathrm{CO}$ \\
\hline SFIT2 & code to retrieve gas profiles from infrared solar absorption spectra \\
\hline SIGIS & Scanning Infrared Gas Imaging System \\
\hline SIMAT & Sistema de Monitoreo Atmosférico \\
\hline SMA-GDF & Secretaría del Medio Ambiente del Gobierno del Distrito Federal \\
\hline T1-site & measurement site during MILAGRO located in Técamac University \\
\hline $\mathbf{S}_{e}$ & measurement noise matrix \\
\hline$\sigma^{*}$ & $\operatorname{Exp}(\operatorname{stdev} .(\ln (x))))$, parameter to describe the variability of a log normal distribution \\
\hline $\mathrm{TC}$ & vertical Total Column of CO \\
\hline $\mathrm{TC}_{\text {IASI }}$ & Total Column of CO measured by IASI \\
\hline TC UNAM & Total CO Column of the reconstructed CO distribution around UNAM \\
\hline TC UNAM & Total CO Column, average of all used UNAM measurements between 11.15 and 13:15 \\
\hline TC UASI & Total CO Column around UNAM obtained from the IASI based reconstructed CO distribution \\
\hline $\mathrm{TC}_{\text {IASSI }}^{\text {day }}$ & Total Column of CO retrieved from day time IASI measurements \\
\hline $\mathrm{TC}_{\text {IASI }}^{\text {night }}$ & Total Column of CO retrieved from nightly IASI measurements \\
\hline TC $_{\text {IASI }}$ & Total Column of CO retrieved from IASI measurements \\
\hline$\left(\frac{\partial \mathrm{TC}}{\partial t}\right)_{\text {advection }}$ & partial column growth-rate of $\mathrm{CO}$ due to advection of polluted airmass \\
\hline$\left(\frac{\partial \mathrm{TC}}{\partial t}\right)_{\text {diffusion }}$ & partial column growth-rate due to decay of anomaly (negative) \\
\hline$\left(\frac{\partial \mathrm{TC}}{\partial t}\right)_{\text {emission }}$ & column growth-rate due to emission of $\mathrm{CO}$ \\
\hline$\left(\frac{\partial \mathrm{TC}}{\partial t}\right)_{\text {inhomogeneity }}$ & column growth-rate due to movement of the LoS due different airmass \\
\hline UNAM & Universidad Nacional Autónoma de México \\
\hline $\mathbf{P F}$ & penalty function \\
\hline$v$ & velocity of the air molecules (wind velocity) \\
\hline$v_{\mathrm{CO}}$ & mean velocity of the $\mathrm{CO}$ molecules \\
\hline$\nabla \cdot \boldsymbol{V}_{\mathrm{CO}}$ & divergence of the mean velocity of only the $\mathrm{CO}$ molecules \\
\hline $\boldsymbol{x}_{\text {avgr.CO }}$ & best estimation of the annual averaged $\mathrm{CO}$ distribution \\
\hline WD,WS & wind direction and wind speed \\
\hline$\phi, \theta$ & azimuth and zenith angles \\
\hline
\end{tabular}

\section{Supplementary material related to this article is available online at: http://www.atmos-chem-phys.net/13/ 1357/2013/acp-13-1357-2013-supplement.pdf.}

Acknowledgements. DGAPA-UNAM is acknowledged for funding this work through project No. IN119310 and two post-doctoral grants. CONACYT funded the scholarships of two graduate students. Ing. Alfredo Rodriguez is thanked for his contribution to the instrumentation. In situ measurements ( $\mathrm{CO}$ and wind data) are provided by the local government, Secretaría del Medio Ambiente del Gobierno del Distrito Federal (SMA-GDF). Therefore we thank Armando Retama Hernández, Director del Sistema de Monitoreo Atmosférico (SIMAT) and his team which are operating the RAMAnetwork and REDMET-network. The data of the official inventory for critical trace gases and green house gases are provided by the
National Institute for Ecology of Mexico, Instituto Nacional de Ecología (INE). Especially we thank Ing. Saúl Rodríguez Rivera for providing the spatial distribution of the official bottom-up inventory for emission of CO. Radiosondes measurements have been provided by the National Weather Service of Mexico (SMN). IASI has been developed and built under the responsibility of the Centre National d'Etudes Spatiales (CNES, France). It is flown onboard the MetOp satellites as part of the Eumetsat Polar System. The IASI L1 data are received through the Eumetcast near real time data distribution service. IASI L1 and L2 data are stored in the Ether atmospheric database http://ether.ipsl.jussieu.fr). The research in France is conducted with the financial support of CNES. The National Center for Atmospheric Research is supported by the National Science Foundation. The NCAR FTIR observation program is supported under contract by the National Aeronautics and Space Administration (NASA). 
Edited by: M. Gauss

\section{References}

Angelbratt, J., Mellqvist, J., Simpson, D., Jonson, J. E., Blumenstock, T., Borsdorff, T., Duchatelet, P., Forster, F., Hase, F., Mahieu, E., De Mazière, M., Notholt, J., Petersen, A. K., Raffalski, U., Servais, C., Sussmann, R., Warneke, T., and Vigouroux, C.: Carbon monoxide $(\mathrm{CO})$ and ethane $\left(\mathrm{C}_{2} \mathrm{H}_{6}\right)$ trends from ground-based solar FTIR measurements at six European stations, comparison and sensitivity analysis with the EMEP model, Atmos. Chem. Phys., 11, 9253-9269, doi:10.5194/acp-11-92532011, 2011.

Bovensmann, H., Buchwitz, M., Burrows, J. P., Reuter, M., Krings, T., Gerilowski, K., Schneising, O., Heymann, J., Tretner, A., and Erzinger, J.: A remote sensing technique for global monitoring of power plant $\mathrm{CO}_{2}$ emissions from space and related applications, Atmos. Meas. Tech., 3, 781-811, doi:10.5194/amt-3-781-2010, 2010.

Clerbaux, C., Edwards, D. P., Deeter, M., Emmons, L., Lamarque, J.-F., Tie, X. X., Massie, S. T., and Gille, J.: Carbon monoxide pollution from cities and urban areas observed by the Terra/MOPITT mission, Geophys. Res. Lett., 35, L03817, doi:10.1029/2007GL032300, 2008a.

Clerbaux, C., George, M., Turquety, S., Walker, K. A., Barret, B., Bernath, P., Boone, C., Borsdorff, T., Cammas, J. P., Catoire, V., Coffey, M., Coheur, P.-F., Deeter, M., De Mazière, M., Drummond, J., Duchatelet, P., Dupuy, E., de Zafra, R., Eddounia, F., Edwards, D. P., Emmons, L., Funke, B., Gille, J., Griffith, D. W. T., Hannigan, J., Hase, F., Höpfner, M., Jones, N., Kagawa, A., Kasai, Y., Kramer, I., Le Flochmoën, E., Livesey, N. J., López-Puertas, M., Luo, M., Mahieu, E., Murtagh, D., Nédélec, P., Pazmino, A., Pumphrey, H., Ricaud, P., Rinsland, C. P., Robert, C., Schneider, M., Senten, C., Stiller, G., Strandberg, A., Strong, K., Sussmann, R., Thouret, V., Urban, J., and Wiacek, A.: CO measurements from the ACE-FTS satellite instrument: data analysis and validation using ground-based, airborne and spaceborne observations, Atmos. Chem. Phys., 8, 2569-2594, doi:10.5194/acp-8-2569-2008, 2008b.

Clerbaux, C., Boynard, A., Clarisse, L., George, M., Hadji-Lazaro, J., Herbin, H., Hurtmans, D., Pommier, M., Razavi, A., Turquety, S., Wespes, C., and Coheur, P.-F.: Monitoring of atmospheric composition using the thermal infrared IASI/MetOp sounder, Atmos. Chem. Phys., 9, 6041-6054, doi:10.5194/acp-9-6041-2009, 2009.

Coffey, M. T., Hannigan, J. W., Goldman, A., Kinnison, D., Gille, J. C., Barnett, J. J., Froidevaux, L., Lambert, A., Santee, M., Livesey, N., Fisher, B., Kulawik, S. S., and Beer, R.: Airborne Fourier transform spectrometer observations in support of EOS Aura validation, J. Geophys. Res.-Atmos., 113, D16S42, doi:10.1029/2007JD008833, 2008.

Crounse, J. D., DeCarlo, P. F., Blake, D. R., Emmons, L. K., Campos, T. L., Apel, E. C., Clarke, A. D., Weinheimer, A. J., McCabe, D. C., Yokelson, R. J., Jimenez, J. L., and Wennberg, P. O.: Biomass burning and urban air pollution over the Central Mexican Plateau, Atmos. Chem. Phys., 9, 4929-4944, doi:10.5194/acp-9-4929-2009, 2009.

de Foy, B., Lei, W., Zavala, M., Volkamer, R., Samuelsson, J., Mellqvist, J., Galle, B., Martínez, A.-P., Grutter, M., Retama, A., and
Molina, L. T.: Modelling constraints on the emission inventory and on vertical dispersion for $\mathrm{CO}$ and $\mathrm{SO}_{2}$ in the Mexico City Metropolitan Area using Solar FTIR and zenith sky UV spectroscopy, Atmos. Chem. Phys., 7, 781-801, doi:10.5194/acp-7781-2007, 2007.

de Foy, B., Fast, J. D., Paech, S. J., Phillips, D., Walters, J. T., Coulter, R. L., Martin, T. J., Pekour, M. S., Shaw, W. J., Kastendeuch, P. P., Marley, N. A., Retama, A., and Molina, L. T.: Basinscale wind transport during the MILAGRO field campaign and comparison to climatology using cluster analysis, Atmos. Chem. Phys., 8, 1209-1224, doi:10.5194/acp-8-1209-2008, 2008.

Emmons, L. K., Edwards, D. P., Deeter, M. N., Gille, J. C., Campos, T., Nédélec, P., Novelli, P., and Sachse, G.: Measurements of Pollution In The Troposphere (MOPITT) validation through 2006, Atmos. Chem. Phys., 9, 1795-1803, doi:10.5194/acp-91795-2009, 2009.

EPA: US Environmental protection agency: Emission Facts: Average Annual Emissions and Fuel Consumption for Passenger Cars and Light Trucks, available at: http://www.epa.gov/otaq/ consumer/f00013.htm (last access: 29 October 2012), 2000.

Finlayson-Pitts, B. and Pitts, J.: Chemistry of the Upper and Lower Atmosphere, Academic Press, San Diego, California, USA, doi:10.1016/B978-012257060-5/50003-4, 2000.

Funke, B., López-Puertas, M., García-Comas, M., Stiller, G. P., von Clarmann, T., Höpfner, M., Glatthor, N., Grabowski, U., Kellmann, S., and Linden, A.: Carbon monoxide distributions from the upper troposphere to the mesosphere inferred from $4.7 \mu \mathrm{m}$ non-local thermal equilibrium emissions measured by MIPAS on Envisat, Atmos. Chem. Phys., 9, 2387-2411, doi:10.5194/acp-92387-2009, 2009.

Geibel, M. C., Gerbig, C., and Feist, D. G.: A fully automated FTIR system for remote sensing of greenhouse gases in the tropics, Atmos. Meas. Tech. Discuss., 3, 3067-3103, doi:10.5194/amtd3-3067-2010, 2010.

George, M., Clerbaux, C., Hurtmans, D., Turquety, S., Coheur, P.F., Pommier, M., Hadji-Lazaro, J., Edwards, D. P., Worden, H., Luo, M., Rinsland, C., and McMillan, W.: Carbon monoxide distributions from the IASI/METOP mission: evaluation with other space-borne remote sensors, Atmos. Chem. Phys., 9, 8317-8330, doi:10.5194/acp-9-8317-2009, 2009.

Gisi, M., Hase, F., Dohe, S., Blumenstock, T., Simon, A., and Keens, A.: $\mathrm{XCO}_{2}$-measurements with a tabletop FTS using solar absorption spectroscopy, Atmos. Meas. Tech. Discuss., 5, 56915724, doi:10.5194/amtd-5-5691-2012, 2012.

Grutter, M.: Multi-Gas analysis of ambient air using FTIR spectroscopy over Mexico City, Atmósfera, 16, 1-13, available at: http:/www.revistas.unam.mx/index.php/atm/article/view/8506 (last access: 29 October 2012), 2003.

Grutter, M., Basaldud, R., Rivera, C., Harig, R., Junkerman, W., Caetano, E., and Delgado-Granados, H.: $\mathrm{SO}_{2}$ emissions from Popocatépetl volcano: emission rates and plume imaging using optical remote sensing techniques, Atmos. Chem. Phys., 8, 6655-6663, doi:10.5194/acp-8-6655-2008, 2008a.

Grutter, M., Basaldud, R., Flores, E., and Harig, R.: Optical Remote Sensing for Characterizing the Spatial Distribution of Stack Emissions, Advanced Environmental Monitoring, Springer Verlag $\mathrm{GmbH}, 2008 \mathrm{~b}$.

Hannigan, J., Coffey, M., Mankin, W., and Goldman, A.: Column observations of stratospheric gases at Sondre Stromfjord, Green- 
land during winter 1994-1995, J. Atmos. Chem., 30, 103-118, 1998.

Hase, F., Demoulin, P., Sauval, A. J., Toon, G. C., Bernath, P. F., Goldman, A., Hannigan, J. W., and Rinsland, C. P.: An empirical line-by-line model for the infrared solar transmittance spectrum from 700 to $5000 \mathrm{~cm}^{-1}$, J. Quant. Spectrosc. Ra., 102, 450-463, doi:10.1016/j.jqsrt.2006.02.026, 2006.

Hauglustaine, D. A., Hourdin, F., Jourdain, L., Filiberti, M.A., Walters, S., Lamarque, J.-F., and Holland, E. A.: Interactive chemistry in the Laboratoire de Météorologie Dynamique general circulation model: description and background tropospheric chemistry evaluation, J. Geophys. Res., 109, 4314-4358, doi:10.1029/2003JD003957, 2004.

Hilton, F., August, T., Barnet, C., Bouchard, A., CamyPeyret, C., Clarisse, L., Clerbaux, C., Coheur, P.-F., Collard, A., Crevoisier, C., Dufour, G., Edwards, D., Faijan, F., Fourrié, N., Gambacorta, A., Gauguin, S., Guidard, V., Hurtmans, D., Illingworth, S., Jacquinet-Husson, N., Kerzenmacher, T., Klaes, D., Lavanant, L., Masiello, G., Matricardi, M., McNally, T., Newman, S., Pavelin, E., Péquignot, E., Phulpin, T., Remedios, J., Schlüssel, P., Serio, C., Strow, L., Taylor, J., Tobin, D., Uspensky, A., and Zhou, D.: Hyperspectral earth observation from IASI: five years of accomplishments, B. Am. Meteorol. Soc., 93, 347-370, doi:10.1175/BAMS-D-11-00027.1, 2012.

Hurtmans, D., Coheur, P.-F., Wespes, C., Clarisse, L., Scharf, O., Clerbaux, C., Hadji-Lazaro, J., George, M., and Turquety, S.: FORLI radiative transfer and retrieval code for IASI, J. Quant. Spectrosc. Ra., 113, 1391-1408, doi:10.1016/j.jqsrt.2012.02.036, 2012.

INEGI: Instituto Nacional de Estadística y Geografía: Censo de Población y Vivienda 2010, available at: http:/www.inegi.org.mx (last access: 3 November 2012), 2011.

Kerzenmacher, T., Dils, B., Kumps, N., Blumenstock, T., Clerbaux, C., Coheur, P.-F., Demoulin, P., García, O., George, M., Griffith, D. W. T., Hase, F., Hadji-Lazaro, J., Hurtmans, D., Jones, N., Mahieu, E., Notholt, J., Paton-Walsh, C., Raffalski, U., Ridder, T., Schneider, M., Servais, C., and De Mazière, M.: Validation of IASI FORLI carbon monoxide retrievals using FTIR data from NDACC, Atmos. Meas. Tech. Discuss., 5, 3973-4002, doi:10.5194/amtd-5-3973-2012, 2012.

Krueger, A., Stremme, W., Harig, R., and Grutter, M.: Volcanic $\mathrm{SO}_{2}$ and $\mathrm{SiF}_{4}$ visualization using 2-D thermal emission spectroscopy - Part 2: Wind propagation and emission rates, Atmos. Meas. Tech., 6, 47-61, doi:10.5194/amt-6-47-2013, 2013.

Limpert, E., Stahel, W. A., and Abbt, M.: Log-normal distributions across the sciences: keys and clues, Bioscience, 51, 341-352, 2001.

Molina, L. T., Madronich, S., Gaffney, J. S., Apel, E., de Foy, B., Fast, J., Ferrare, R., Herndon, S., Jimenez, J. L., Lamb, B., Osornio-Vargas, A. R., Russell, P., Schauer, J. J., Stevens, P. S., Volkamer, R., and Zavala, M.: An overview of the MILAGRO 2006 Campaign: Mexico City emissions and their transport and transformation, Atmos. Chem. Phys., 10, 8697-8760, doi:10.5194/acp-10-8697-2010, 2010.

Nedelec, P., Cammas, J.-P., Thouret, V., Athier, G., Cousin, J.-M., Legrand, C., Abonnel, C., Lecoeur, F., Cayez, G., and Marizy, C.: An improved infrared carbon monoxide analyser for routine measurements aboard commercial Airbus aircraft: technical validation and first scientific results of the MOZAIC III programme,
Atmos. Chem. Phys., 3, 1551-1564, doi:10.5194/acp-3-15512003, 2003.

Ortega, I.: Espectroscopía FTIR de absorción solar y lunar para la determinación en la columna de $\mathrm{CO}$ en la capa de mezcla de la Ciudad de México, Master's thesis, Universidad Nacional Autónoma de México, México City, Mexico, http://www.atmosfera.unam.mx/espectroscopia/thesis/MSc_ Ivan_Ortega.pdf, (last access: 2 November 2012) 2009.

PEMEX: Petróleos Mexicanos: Hoja de datos de seguridad de sustancias PEMEX Magna. Subdirección de Auditoría en Seguridad Industrial y Protección Ambiental. Gerencia de Seguridad Industrial y Salud Ocupacional. PEMEX Refinación., available at: http://www.pemex.com/index.cfm?action= content\&sectionID $=4 \&$ catID $=10015$ (last access: 2 November 2012), 2008.

PEMEX: Petróleos Mexicanos: Indicadores Petroleros: informe mensual sobre producción y comercio de hidrocarburos. Septiembre 2011, Vol. XXIII, Núm. 9. Subdirección de Planeación Económica. Gerencia de Integración de Información Institucional., available at: http://www.ri.pemex.com/index.cfm? action $=$ content $\&$ sectionID $=16 \&$ catID $=12155$ (last access: 2 November 2012), 2011.

Pommier, M., Law, K. S., Clerbaux, C., Turquety, S., Hurtmans, D., Hadji-Lazaro, J., Coheur, P.-F., Schlager, H., Ancellet, G., Paris, J.-D., Nédélec, P., Diskin, G. S., Podolske, J. R., Holloway, J. S., and Bernath, P.: IASI carbon monoxide validation over the Arctic during POLARCAT spring and summer campaigns, Atmos. Chem. Phys., 10, 10655-10678, doi:10.5194/acp-1010655-2010, 2010.

Pougatchev, N. S. and Rinsland, C. P.: Spectroscopic study of the seasonal variation of carbon monoxide vertical distribution above Kitt Peak, J. Geophys. Res., 100, 1409-1416, doi:10.1029/94JD02387, 1995.

Rakitin, V. S., Fokeeva, E. V., Grechko, E. I., Dzhola, A. V., and Kuznetsov, R. D.: Variations of the total content of carbon monoxide over Moscow megapolis, Izv. Atmos. Ocean. Phy.+, 47, 59-66, doi:10.1134/S0001433810051019, 2011.

Rakitin, V., Dzhola, A., Fokeeva, E., Grechko, E., and Starikova, E.: Long-term variations of $\mathrm{CO}$ total column over Moscow and its outskirts, in: EGU General Assembly Conference Abstracts, edited by: Abbasi, A. and Giesen, N., vol. 14 of EGU General Assembly Conference Abstracts, 521, Vienna, Austria, 22-27 April 2012, 2012.

Rinsland, C. P., Smith, M. A. H., Rinsland, P. L., Goldman, A., Brault, J. W., and Stokes, G. M.: Ground-based infrared spectroscopic measurements of atmospheric hydrogen cyanide, J. Geophys. Res.-Atmos., 87, 11119-11125, doi:10.1029/JC087iC13p11119, 1982.

Rodgers, C. D.: Characterization and error analysis of profiles retrieved from remote sounding measurements, J. Geophys. Res., 95, 5587-5595, 1990.

Rodgers, C. D.: Inverse methods for atmospheric sounding: theory and practice, Ser. Atmos. Oceanic Planet. Phys., 2, World Sci., Hackensack, N. J., 2000.

Rodgers, C. D. and Connor, B. J.: Intercomparison of remote sounding instruments, J. Geophys. Res.-Atmos., 108, 4116, doi:10.1029/2002JD002299, 2003.

Rothman, L. S., Jacquemart, D., Barbe, A., Chris Benner, D., Birk, M., Brown, L. R., Carleer, M. R., Chackerian, C., 
Chance, K., Coudert, L. H., Dana, V., Devi, V. M., Flaud, J.-M., Gamache, R. R., Goldman, A., Hartmann, J.-M., Jucks, K. W., Maki, A. G., Mandin, J.-Y., Massie, S. T., Orphal, J., Perrin, A., Rinsland, C. P., Smith, M. A. H., Tennyson, J., Tolchenov, R. N., Toth, R. A., Vander Auwera, J., Varanasi, P., and Wagner, G.: The HITRAN 2004 molecular spectroscopic database, J. Quant. Spectrosc. Ra., 96, 139-204, doi:10.1016/j.jqsrt.2004.10.008, 2005.

SIMAT: Sistema de Monitoreo Atmosférico de la Ciudad de México, available at: http://www.calidadaire.df.gob.mx/ calidadaire/ (last access: 2 November 2012), 2011.

SEMARNAT: Secretaría del Medio Ambiente y Recursos Naturales. Norma Oficial Mexicana NOM-041-SEMARNAT-2006, que establece los límites máximos permisibles de emisión de gases contaminantes provenientes del escape de los vehículos automotores en circulación que usan gasolina como combustible, available at: http://www.semarnat.gob.mx/leyesynormas/Pages/ fuentesmoviles.aspx (last access: 2 November 2012), 2006.

SMA-GDF: Secretaría del Medio Ambiente del Gobierno del Distrito Federal: Calidad del Aire en la Ciudad de México: Informe 2008, available at: http://www.sma.df.gob.mx/sma/ links/download/archivos/informe2008/informe_anual_2008.pdf (last access: 2 November 2012), 2009.

SMA-GDF: Secretaría del Medio Ambiente del Gobierno del Distrito Federal: Inventario de emisiones de contaminantes criterio de la ZMVM 2008, available at: http://www.sma.df.gob.mx (last access: 2 November 2012), 2010a.

SMA-GDF: Inventario de emisiones de gases de efecto invernadero y carbón negro de la ZMVM 2008, available at: http://www.sma. df.gob.mx (last access: 2 November 2012), 2010b.

Steck, T.: Methods for determining regularization for atmospheric retrieval problems, Appl. Opt., 41, 1788-1797, doi:10.1364/AO.41.001788, 2002.

Stremme, W., Ortega, I., and Grutter, M.: Using ground-based solar and lunar infrared spectroscopy to study the diurnal trend of carbon monoxide in the Mexico City boundary layer, Atmos. Chem. Phys., 9, 8061-8078, doi:10.5194/acp-9-8061-2009, 2009.

Stremme, W., Ortega, I., Siebe, C., and Grutter, M.: Gas composition of Popocatepetl Volcano between 2007 and 2008: FTIR spectroscopic measurements of an explosive event and during quiescent degassing, Earth Planet. Sc. Lett., 301, 502-510, doi:10.1016/j.epsl.2010.11.032, 2011.

Stremme, W., Krueger, A., Harig, R., and Grutter, M.: Volcanic $\mathrm{SO}_{2}$ and $\mathrm{SiF}_{4}$ visualization using 2-D thermal emission spectroscopy - Part 1: Slant-columns and their ratios, Atmos. Meas. Tech., 5, 275-288, doi:10.5194/amt-5-275-2012, 2012.

Té, Y., Dieudonné, E., Jeseck, P., Hase, F., Hadji-Lazaro, J., Clerbaux, C., Ravetta, F., Payan, S., Pépin, I., Hurtmans, D., Pelon, J., and Camy-Peyret, C.: Carbon monoxide urban emission monitoring: a ground-based FTIR case study, J. Atmos. Ocean. Tech., 29, 911-921, doi:10.1175/JTECH-D-11-00040.1, 2012.
Turquety, S., Clerbaux, C., Law, K., Coheur, P.-F., Cozic, A., Szopa, S., Hauglustaine, D. A., Hadji-Lazaro, J., Gloudemans, A. M. S., Schrijver, H., Boone, C. D., Bernath, P. F., and Edwards, D. P.: CO emission and export from Asia: an analysis combining complementary satellite measurements (MOPITT, SCIAMACHY and ACE-FTS) with global modeling, Atmos. Chem. Phys., 8, 5187-5204, doi:10.5194/acp-8-5187-2008, 2008.

Turquety, S., Hurtmans, D., Hadji-Lazaro, J., Coheur, P.-F., Clerbaux, C., Josset, D., and Tsamalis, C.: Tracking the emission and transport of pollution from wildfires using the IASI CO retrievals: analysis of the summer 2007 Greek fires, Atmos. Chem. Phys., 9, 4897-4913, doi:10.5194/acp-9-4897-2009, 2009.

Velasco, E., Pressley, S., Grivicke, R., Allwine, E., Coons, T., Foster, W., Jobson, B. T., Westberg, H., Ramos, R., Hernández, F., Molina, L. T., and Lamb, B.: Eddy covariance flux measurements of pollutant gases in urban Mexico City, Atmos. Chem. Phys., 9, 7325-7342, doi:10.5194/acp-9-7325-2009, 2009.

Velazco, V. A., Buchwitz, M., Bovensmann, H., Reuter, M., Schneising, O., Heymann, J., Krings, T., Gerilowski, K., and Burrows, J. P.: Towards space based verification of $\mathrm{CO}_{2}$ emissions from strong localized sources: fossil fuel power plant emissions as seen by a CarbonSat constellation, Atmos. Meas. Tech., 4, 2809-2822, doi:10.5194/amt-4-2809-2011, 2011.

von Clarmann, T. and Grabowski, U.: Elimination of hidden a priori information from remotely sensed profile data, Atmos. Chem. Phys., 7, 397-408, doi:10.5194/acp-7-397-2007, 2007.

von Clarmann, T., Grabowski, U., and Kiefer, M.: On the role of non-random errors in inverse problems in radiative transfer and other applications,J. Quant. Spectrosc. Ra., 71, 39-46, 2001.

Wunch, D., Wennberg, P. O., Toon, G. C., Keppel-Aleks, G., and Yavin, Y. G.: Emissions of greenhouse gases from a North American megacity, Geophys. Res. Lett., 36, 15 810-15815, doi:10.1029/2009GL039825, 2009.

Yokelson, R. J., Urbanski, S. P., Atlas, E. L., Toohey, D. W., Alvarado, E. C., Crounse, J. D., Wennberg, P. O., Fisher, M. E., Wold, C. E., Campos, T. L., Adachi, K., Buseck, P. R., and Hao, W. M.: Emissions from forest fires near Mexico City, Atmos. Chem. Phys., 7, 5569-5584, doi:10.5194/acp-7-5569-2007, 2007.

Yurganov, L. N., Rakitin, V., Dzhola, A., August, T., Fokeeva, E., George, M., Gorchakov, G., Grechko, E., Hannon, S., Karpov, A., Ott, L., Semutnikova, E., Shumsky, R., and Strow, L.: Satellite- and ground-based CO total column observations over 2010 Russian fires: accuracy of top-down estimates based on thermal IR satellite data, Atmos. Chem. Phys., 11, 7925-7942, doi:10.5194/acp-11-7925-2011, 2011. 